October 2000 - NREL/TP-520-28941

\title{
Improved Radiometric Calibrations and Measurements for Evaluating Photovoltaic Devices
}

Daryl R. Myers

Thomas L. Stoffel

Afshin Andreas Stephen Wilcox Ibrahim Reda

\section{National Renewable Energy Laboratory}

1617 Cole Boulevard Golden, Colorado 80401-3393

NREL is a U.S. Department of Energy Laboratory Operated by Midwest Research Institute $\bullet$ Battelle $\bullet$ Bechtel 


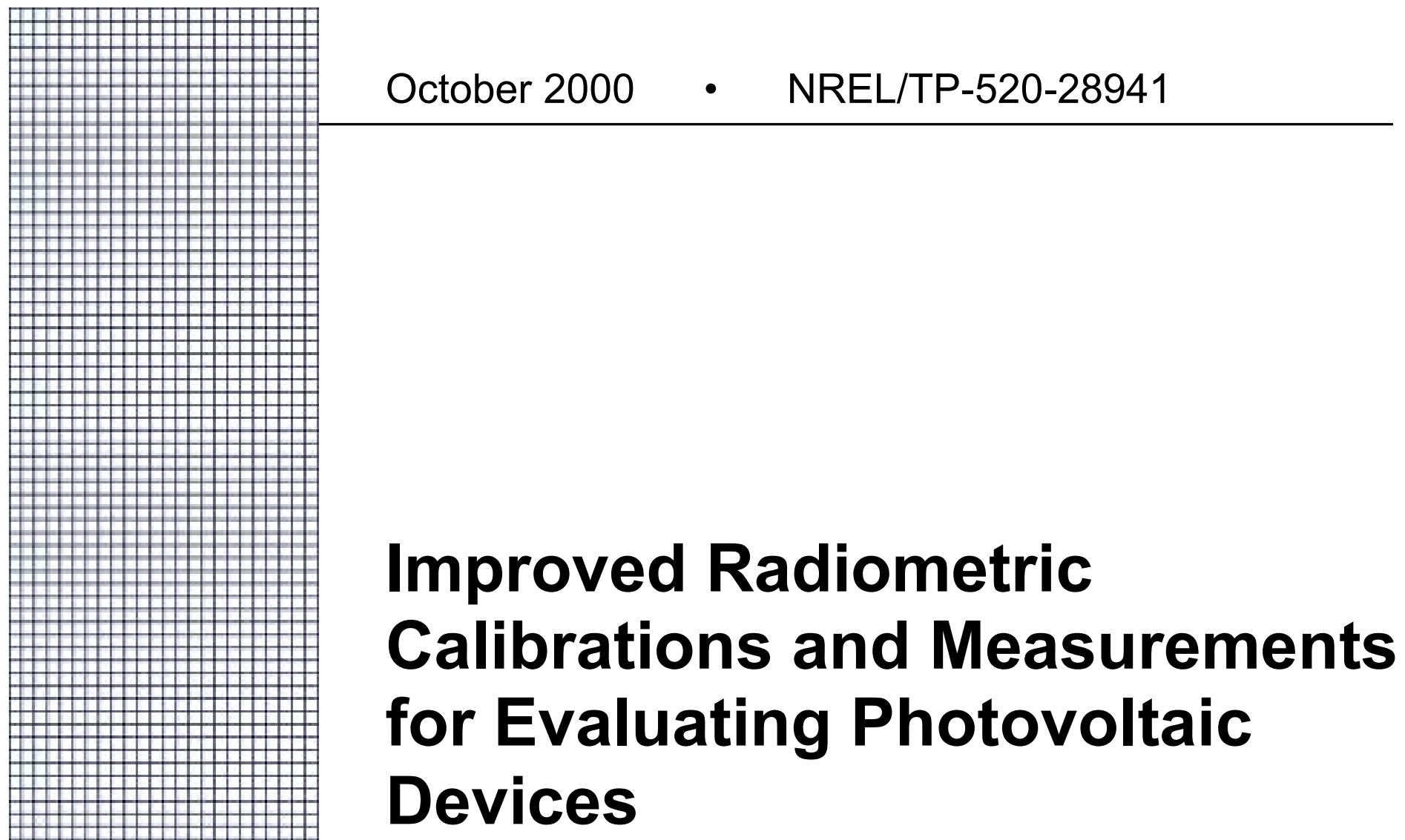

Daryl R. Myers

Thomas L. Stoffel

Afshin Andreas

Stephen Wilcox

Ibrahim Reda

Prepared under Task No. PVP17401

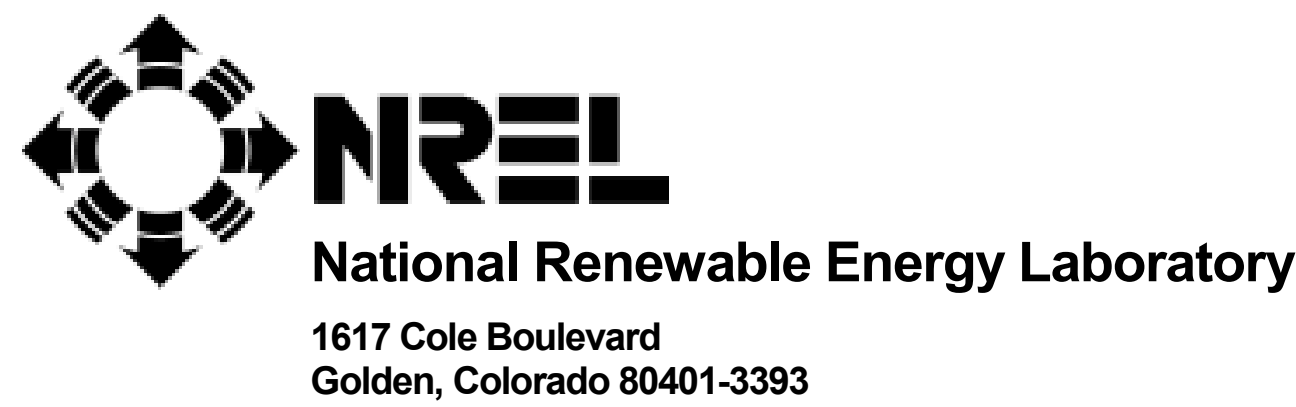

NREL is a U.S. Department of Energy Laboratory

Operated by Midwest Research Institute $\bullet$ Battelle $\bullet$ Bechtel

Contract No. DE-AC36-99-G010337 


\section{NOTICE}

This report was prepared as an account of work sponsored by an agency of the United States government. Neither the United States government nor any agency thereof, nor any of their employees, makes any warranty, express or implied, or assumes any legal liability or responsibility for the accuracy, completeness, or usefulness of any information, apparatus, product, or process disclosed, or represents that its use would not infringe privately owned rights. Reference herein to any specific commercial product, process, or service by trade name, trademark, manufacturer, or otherwise does not necessarily constitute or imply its endorsement, recommendation, or favoring by the United States government or any agency thereof. The views and opinions of authors expressed herein do not necessarily state or reflect those of the United States government or any agency thereof.

Available electronically at http://www.doe.gov/bridge

Available for a processing fee to U.S. Department of Energy

and its contractors, in paper, from:

U.S. Department of Energy

Office of Scientific and Technical Information

P.O. Box 62

Oak Ridge, TN 37831-0062

phone: 865.576.8401

fax: 865.576.5728

email: reports@adonis.osti.gov

Available for sale to the public, in paper, from:

U.S. Department of Commerce

National Technical Information Service

5285 Port Royal Road

Springfield, VA 22161

phone: 800.553.6847

fax: 703.605.6900

email: orders@ntis.fedworld.gov

online ordering: http://www.ntis.gov/ordering.htm

Printed on paper containing at least $50 \%$ wastepaper, including $20 \%$ postconsumer waste 


\section{Preface}

In the period from October 1998 to September 2000, the Photovoltaic Radiometric Measurements Task has improved broadband and spectral measurement capabilities at NREL. These improved NREL's capabilities affect the Photovoltaic Module and Array Performance and Reliability and Photovoltaic Measurements and Characterization Projects. Recent improvements (during 2000) in broadband radiometer calibrations result in the removal of bias errors on the order of 20 watts per square meter $\left(\mathrm{W} / \mathrm{m}^{2}\right)$ in the measurement of global-hemispherical solar radiation. The improvements described are partially due to technical interactions by members of the Measurements and Instrumentation Team with the U.S. Department of Energy Atmospheric Radiation Measurement Program (ARM), National Aeronautics and Space Administration (NASA) Earth Observing System (EOS) Validation Program, World Meteorological Organization (WMO) Baseline Surface Measurement Network (BSRN), and National Oceanic and Atmospheric Administration (NOAA) Solar Radiation Research Branch (SRRB). New equipment has been purchased and techniques have been developed to characterize pulsed solar simulator spectral distributions. New equipment has been purchased and will be installed in the redesigned Solar Radiation Research Laboratory (SRRL) Baseline Measurement System (BMS). Expanded measurement capability, including sky radiance mapping, extensive ultraviolet and infrared radiation measurements, and routine spectral sampling will provide a unique complement of data for investigating PV device, module, and system design and performance, model development and validation, and for evaluating new measurement systems. 


\section{Contents}

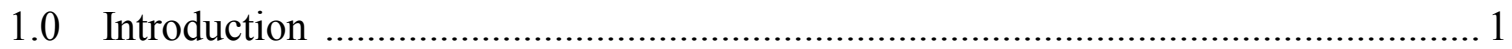

2.0 Revising Broadband Outdoor Radiometer Calibrations (BORCAL) ........................ 2

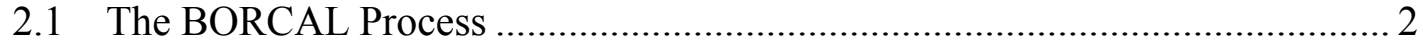

2.2 Radiometer Calibration and Characterization (RCC) ............................... 5

2.3 Diffuse Irradiance and Thermal Offsets ......................................................... 6

2.4 RCC Reporting .................................................................................... 7

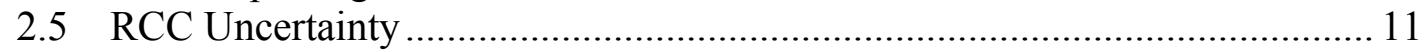

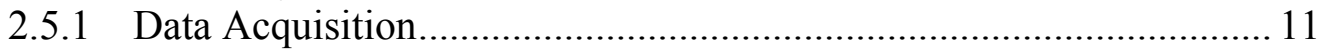

2.5.2 Transfer of World Radiometric Reference ......................................... 11

2.5.3 Zenith-Angle Computation ................................................................. 12

2.5.4 Reference Diffuse-Sky Irradiance .............................................. 12

2.5.5 Total Uncertainty Calculation ................................................... 12

2.6 Results and Impact of RCC/BORCAL Revisions ...................................... 14

3.0 Applying Responsivity as a Function of Zenith Angle ....................................... 14

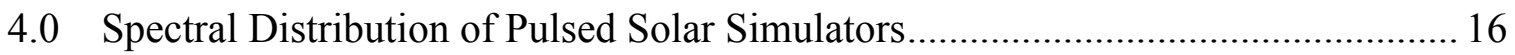

4.1 Pulse Analysis Spectrometer System (PASS) ........................................... 19

4.2 Optronic Laboratories (OL) Pulse Energy Measurements .............................. 20

4.3 Analytical Spectral Devices (ASD) Diode Array Spectrometer..................... 20

4.4 Spectral Drift of the Spire 240A Pulsed Solar Simulator............................... 21

4.5 Spectral Measurements of the NREL Spectrolab Pulse Solar Simulators ...... 25

5.0 Upgrading Solar Radiation Research Laboratory Instrumentation ....................... 26

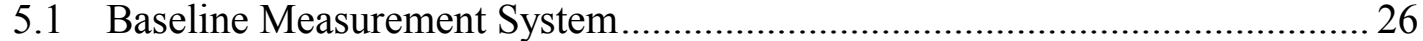

5.2 Sky Camera Archive and Sky Radiance Mapping ......................................... 27

5.3 New SRRL Baseline Measurement Instrumentation...................................... 29

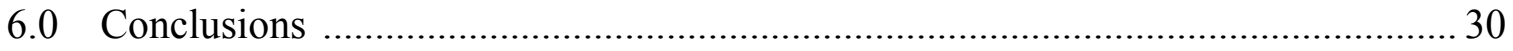

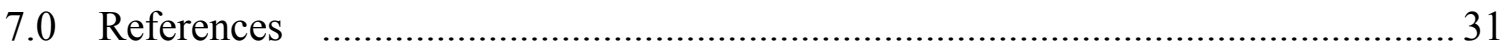




\section{List of Figures}

1.1. Pyrheliometers for measuring direct-normal solar radiation .............................. 1

1.2. Pyranometer for measuring global-hemispherical radiation ................................ 1

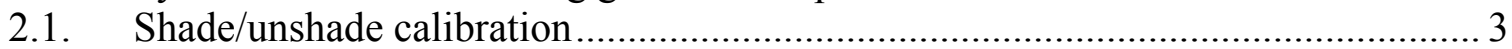

2.2. Component summation calibration ................................................................. 3

2.3. ASTM sequence for shade/unshade calibration procedures................................. 3

2.4. Tracking shading disk for pyranometer measurement of diffuse-sky radiation ...... 4

2.5. All-black (top unit) and black-and-white thermopile pyranometers under tracking shading disks

2.6. Clear-sky diffuse irradiance under tracking shading disks for an all-black (lower line) and black-and-white (upper line) pyranometers at NREL

2.7 Reference global irradiance and direct and diffuse components from which it was computed (top panel). Ratio of diffuse-sky irradiance to total global reference irradiance (bottom panel)

2.8. Meteorological observations recorded during RCC/BORCAL data collection. Aerosol optical depth or turbidity (top panel), relative humidity (middle panel), and ambient temperature (bottom panel). Conditions on at least four different days are identifiable.

2.9. Pyranometer cosine response curve generated by RCC. Morning data is "top" leg, and afternoon data is the "bottom" leg. Horizontal bars are mean responsivity in zenith-angle ranges spanned by the bars

3.1. Reducing absolute error in measured pyranometer global irradiance (GLO PSP) using zenith angle corrections. Top black curve is measured global irradiance using single (45-55 bin) responsivity. The next curve down (thick black line, $\operatorname{Gcor}(Z))$ is the measured global irradiance after correcting the measured data with responsivity for the appropriate zenith-angle bin. The third line down (thin gray line, $\mathrm{B} \& \mathrm{~W}+\mathrm{DN}$ GLO) is the global irradiance computed from a pyrheliometer and black-and-white shaded pyranometer. Thick gray line (fourth from top) is the pyrheliometer data (DIR (NIP)), and the gray line at the bottom is the shaded black-and-white pyranometer diffuse (SD 848) ................................................ 15

3.2. Partly cloudy day (June 19, 2000) example for applying zenith-angle bin responsivities to measured global total irradiance for the same pyranometer as in Figure 3.1. Shaded black-and-white sky diffuse is very light gray line at bottom. Differences between corrected and uncorrected data are only barely discernable in the clear-sky data before 9 A.M

4.1. Commercial solar simulator for photovoltaic testing and research ..................... 17

4.2. Typical time series profile for pulse solar simulator light flash ......................... 17

4.3. ASTM Reference spectra E-891 (global spectral irradiance on a $37^{\circ}$ south-facing tilted surface at Air Mass 1.5) and E-892 (air mass 1.5 direct-normal spectral irradiance). Atmospheric conditions are specified as visibility of $23 \mathrm{~km}$, aerosol optical depth of 0.27 , total precipitable water of $1.42 \mathrm{~cm}$, and total column ozone

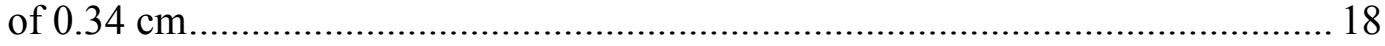

4.4. The PASS system equipment being set up to measure the spectral distribution of a pulse solar simulator. Left to right: control computer, monochromator interface, amplifiers, pulse generator, digital oscilloscope (box), and monochromator (circle) 
4.5. Optronic Laboratories OL-750 spectrometer for pulse integration measurements ....

4.6. ASD Spectrometer with electronics housed under portable computer. Remote cosine receptor at left, with fiber optic link to spectrometer.

4.7. Relative magnitudes of PASS, ASD, and OL-750 pulse integration spectral data on semi-logarithmic scale. Variations in detail are due to different spectral passbands of the measurements ( $5 \mathrm{~nm}$ for PASS up to $1100 \mathrm{~nm}$, where it changes to $10 \mathrm{~nm}$; ASD and OL -750 passband is about $5 \mathrm{~nm}$, but the ASD data are at 1$\mathrm{nm}$ resolution and the OL-750 is at 5-nm resolution).

4.8. Spectral distributions of Figure 4.7 normalized to maximum irradiance between 450 and $500 \mathrm{~nm}$ for each distribution.

4.9. Comparison of normalized April 1999 OL-750 spectrum (heavy line) with September 1999 (lowest light line) and August 2000 OL-750 spectrum (middle thin line) showing 10\% loss of energy in visible spectrum over 8 months

4.10. Relative shifts in spectral distribution of the NREL Spire 240A solar simulator with respect to April 1999 baseline measurement. Lines are ratios of measured data in month indicated to April 1999 measurement. Data were collected using the OL-750 pulse energy measurement spectroradiometer system. Noise in ratios beyond $900 \mathrm{~nm}$ is due to variations in intensity of spectral emission lines and spectrometer wavelength drive.

4.11. Comparison of ratio of April 1999 to September 1999 spectral data files for both ASD and OL-750 spectrometer systems, confirming approximately 5\% to $10 \%$ degradation in NREL Spire 240A intensity in the visible region...

4.12. LAPSS (left) and HIPSS (right) flash-lamp apertures (a). The intensity of the HIPSS is controlled by the setting of sliding shutter blades (b) .........................25

4.13. Relative spectral distribution of the normalized HIPSS (heavy line) and LAPSS (thin black line) with respect to ASTM global reference spectrum E 892 (gray line). Variations in two measured spectra are due to slightly different passbands and spectral resolution of the PASS and OL750 systems ....

5.1. New SRRL/Metrology/Optics Lab building (left) and solar radiation measurement platform to west of building (right) ................................................................ 26

5.2. SRRL all-sky camera gallery for September 2, 2000 .................................... 27

5.3. Sky luminance plot (right) compared with sky camera image for noon, June 15, 2000 showing brightness distribution around noontime sun..............................227

5.4. Comparison of diffuse-sky measurements by black-and-white pyranometer under tracking shading disk (black line) with integrated Eko sky scanner radiance data (gray line) for June 19, 2000. The diffuse pyranometer data are 1-minute data, and the sky-scanner data are the integral of measurements archived at 15-minute intervals 28

5.5. Plot of relative contribution (percent) of diffuse-sky radiance to the total diffusesky component during BORCAL event 2000-01, June 21, 2000. Contours show percent of total diffuse sky for each zenith/elevation angle element of the sky as a function of time of day 28

5.6. SRRL Baseline Measurement Platform and instrument complement.................. 29 


\section{List of Tables}

2.1. RCC report of mean pyranometer responsivity within zenith-angle bins ............ 10

4.1. Spire 240A PV device measurements over period of spectral monitoring ........... 23 


\subsection{Introduction}

Evaluating photovoltaic (PV) cells, modules, and arrays, and systems performance relies on the accurate measurement of the available solar radiation resources for conversion. Pyrheliometers (Figure 1.1) measure the shortwave $(0.3$ micrometer to 2.5 micrometer wavelength) solar radiation direct-beam radiation within a $5^{\circ}$ field of view around the solar disk. Pyranometers (Figure 1.2) measure the total shortwave solar radiation, also called global or hemispherical solar radiation, in a hemispherical ( $2 \pi$ steradian) field of view. Pyranometer measurements are used to characterize performance of flat-plate PV technologies, and pyrheliometer measurements are important for concentrating solar collector technologies.

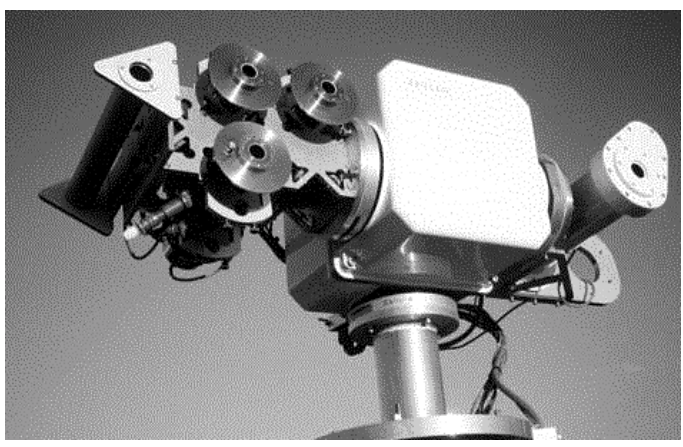

Figure 1.1 Pyrheliometers for measuring direct-normal solar radiation.

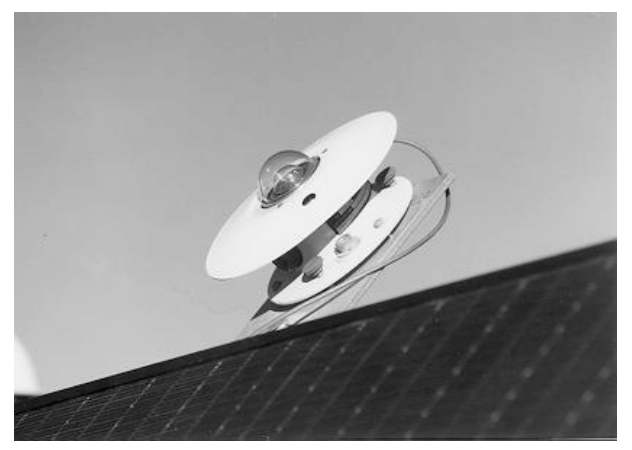

Figure 1.2 Pyranometer for measuring global-hemispherical radiation.

The ratio between the pyranometer output signal (measured in microvolts) and the intensity of the solar power flux (measured in watts per square meter) is known as the calibration factor. NREL's Measurements and Instrumentation Team developed Broadband Outdoor Radiometer Calibration (BORCAL) procedures to characterize and calibrate pyrheliometers and pyranometers. These procedures refined and improved our Radiometric Calibration (RADCAL) techniques (described in Myers, 1988; Myers et al., 1989; Myers, 1989; and Myers and Stoffel, 1990). The vehicle for implementing BORCAL data collection, reporting, and data archiving is our Radiometer Calibration and Characterization (RCC) software developed by the Measurements and Instrumentation Team (NREL, 1997).

Members of the Measurements and Instrumentation Team have worked with the U.S. Department of Energy (DOE) Atmospheric Radiation Measurement Program (ARM), National Aeronautics and Space Administration (NASA) Earth Observing System (EOS) Validation Program, World Meteorological Organization (WMO) Baseline Surface Measurement Network (BSRN), and National Oceanic and Atmospheric Administration (NOAA) Solar Radiation Research Branch (SRRB) to identify, characterize, and reduce sources of error and uncertainty in broadband shortwave radiation calibrations and measurements (Dutton et al., 2000; Stoffel et al., 1999; Reda and Myers, 1999; Wilcox et al., 1999; Wilcox and Stoffel, 1998). Section 2 below addresses the identification, 
characterization, and corrections for thermal offsets and non-uniform geometrical cosine response for all-black pyranometers.

Commercially available pulsing or flashing solar simulators are used in the PV industry to evaluate the performance of modules in the production environment. NREL uses several such sources to produce initial or as-received PV device performance data, and to monitor module performance over time. These sources can also be used for various research purposes, such as determining temperature or irradiance coefficients of various parameters (e.g., open-circuit voltage, short-circuit current [Kroposki et al., 1996]). As many different PV materials and technologies are tested, it is important to know the spectral distribution of these sources, both for spectral mismatch calculations and for establishing corrections for deviation from the American Society for Testing and Materials (ASTM) reference global spectrum (ASTM 1997a). Section 3 describes how we have recently (during 1999 and 2000) developed methods to measure these spectral distributions, and discusses some recent results.

The Measurements and Instrumentation Team maintains and operates the Solar Radiation Research Laboratory (SRRL) as a monitoring, calibration, and research facility to provide short- and long-term solar radiation data to meet the needs of researchers in the NREL PV and other DOE renewable energy programs. Section 4 describes upgrades to the SRRL complement of instrumentation and Internet access to data accomplished in the 19992000 timeframe.

\subsection{Revising Broadband Outdoor Radiometer Calibrations (BORCAL)}

\subsection{The BORCAL Process}

The World Meteorological Organization (WMO) World Radiometric Reference (WRR) is the basis for NREL's BORCAL procedures for calibrating pyrheliometers and pyranometers. The WRR is maintained as the world reference for measuring the directbeam solar irradiance using absolute-cavity pyrheliometers (Kendall and Berhdahl, 1970; Willson, 1973; WMO, 1983; Reda, 1996; Wilcox et al., 1999).

Transfer of a WRR traceable calibration to pyrheliometers used in the field is done by direct comparison of an absolute-cavity pyrheliometer and the pyrheliometer under test (ASTM 1997c; Zerlaut, 1986; Zerlaut, 1989). Transfer of a WRR traceable calibration to field pyranometers can be done using an absolute-cavity pyrheliometer and a shade/unshade procedure for the test pyranometers summarized below (ASTM 1997d; Reda and Myers, 1999). Alternatively, a reference irradiance from an absolute-cavity pyrheliometer direct-beam measurement and a diffuse-sky radiation measurement can be computed (Myers and Stoffel, 1990). This latter technique is the "component summation" method. The diffuse-sky radiation must be measured with a pyranometer under a suntracking shading disk that blocks the same solid angle as the field of view of the cavity pyrheliometer. Figures 2.1 and 2.2 show schematics of the shade/unshade and component summation techniques, respectively. 
In the shade/unshade protocol, the responsivity, Rs, is the ratio of the pyranometer signal (microvolts) to the input signal (watts per square meter, $\mathrm{W} / \mathrm{m}^{2}$ ) due to the vertical component of the direct beam, $\mathrm{I}_{\mathrm{dn}}$. The vertical component of the direct-beam irradiance is $I_{\mathrm{dn}}$ multiplied by the cosine of the zenith angle (the angle between the zenith point and the sun). By shading the pyranometer with a disk subtending the $5^{\circ}$ degree solid angle as the field of view of a cavity pyrheliometer, the vertical component of the direct beam is removed, thus producing a signal $\mathrm{Vs}$. The unshaded signal is $\mathrm{Vu}$, and the responsivity is computed as:

$$
R s=\frac{V u-V s}{I_{d n} \bullet \operatorname{Cos}(z)}
$$

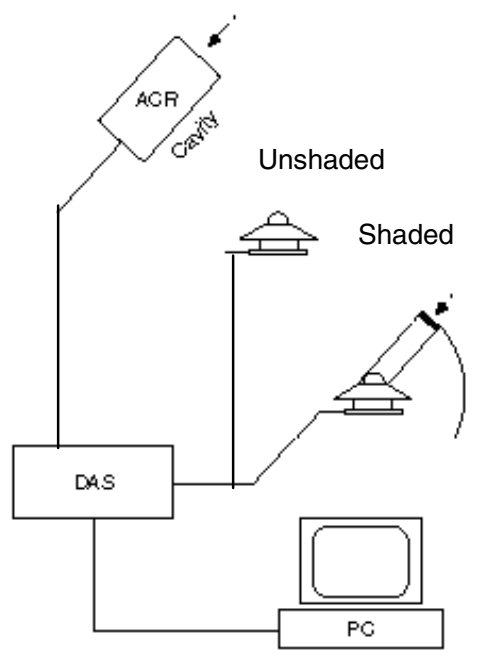

Figure 2.1. Shade/Unshade Calibration.

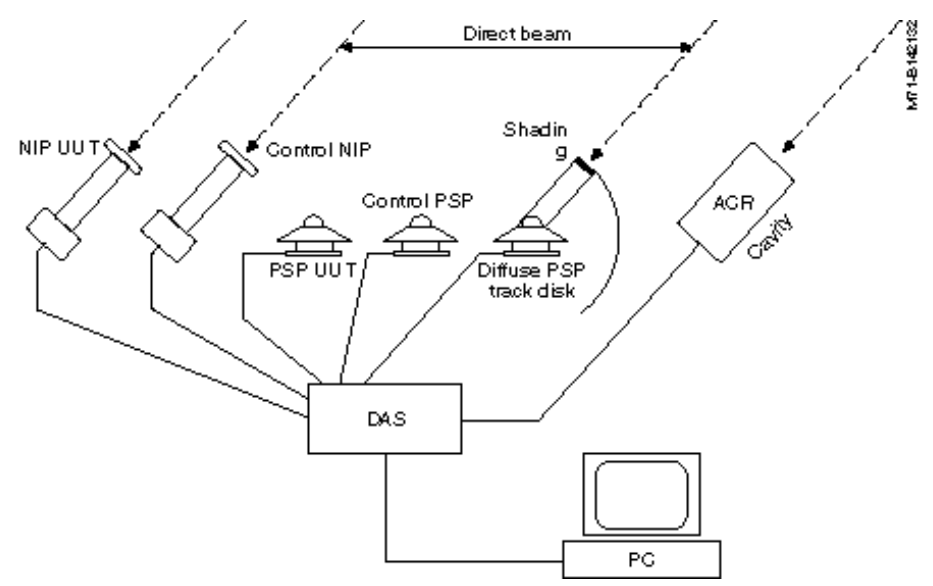

Figure 2.2. Component Summation Calibration.

The detailed procedures and suggested timing sequence for acquiring the data for the shade/unshade calibration are described in the American Society for Testing and

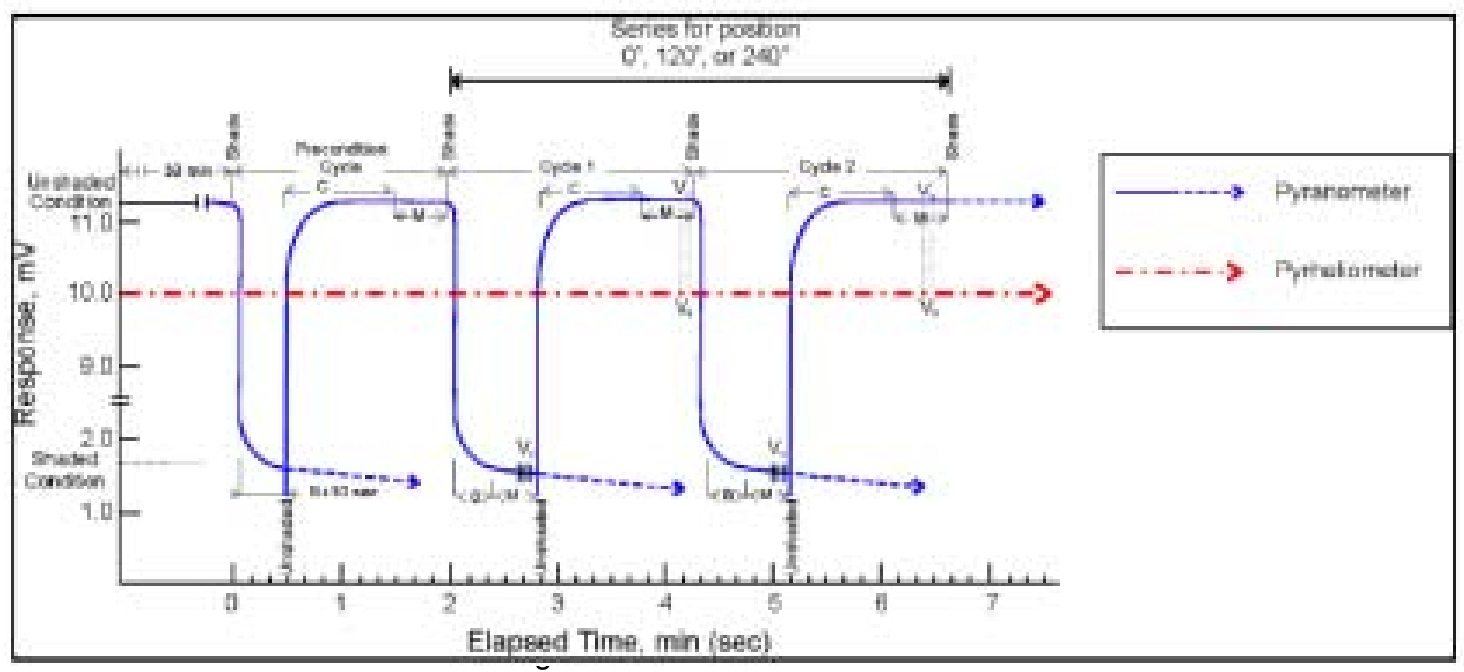

Figure 2.3. ASTM sequence for shade/unshade calibration procedures. 
Materials (ASTM) Standard 913: Standard Method for Calibration of Reference Pyranometers with Axis Vertical by the Shading Method (ASTM 1997d). The measurement and timing sequence for the shade/unshade approach is shown in Figure 2.3. The time period $\mathrm{A}$ is a 30-minute warm-up period for allowing the instrument to stabilize. Time period B represents 20 to 30 time constants (1/e, or $63 \%$ of final steadystate values) for the instrument response. Period $\mathrm{C}$ represents 60 time constants for the instrument response. Period $\mathrm{M}$ is the time during which at least three readings of instrument response, $\mathrm{Vs}$ or $\mathrm{Vu}$, and the direct-beam irradiance, are recorded. The mean zenith angle and cavity pyrheliometer data during the measurement periods $M$ are used in computing the $\mathrm{I}_{\mathrm{dn}} \bullet \operatorname{Cos}(\mathrm{z})$ terms.

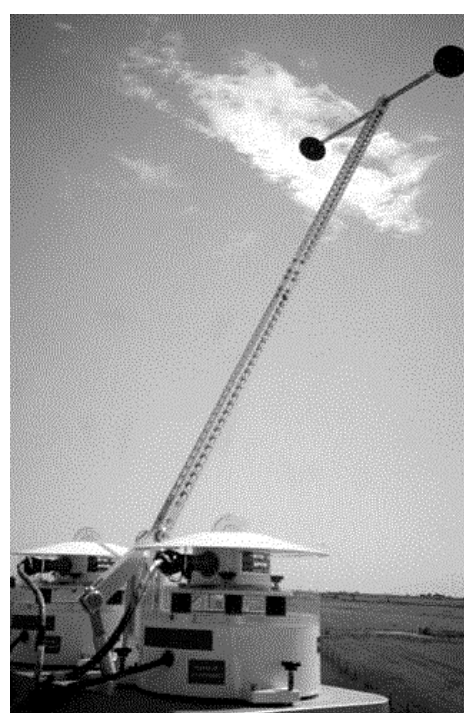

Figure 2.4. Tracking shading disk for pyranometer measurement of diffuse-sky radiation.

To calibrate many field radiometers simultaneously, it is convenient to implement the "component summation" technique shown in Figure 2.2. For this technique, a pyranometer for measuring the diffuse-sky irradiance uses a tracking shading disk, as shown in Figure 2.4. The pyranometer(s) used under the tracking shading disk must first be calibrated using the shade/unshade technique.

The first improvement implemented in the NREL BORCAL procedures was to characterize the responsivity of the pyranometer used to measure the diffuse-sky radiation as the mean of the responsivities in three azimuthal directions $\left(0^{\circ}, 120^{\circ}\right.$, and $\left.240^{\circ}\right)$ with respect to south $=0^{\circ}$. A detailed uncertainty analysis of this refined approach [Reda and Myers, 1999] results in a total uncertainty of $2.5 \%$ in the calibration factor for measuring total diffuse-sky irradiance $\left(\mathrm{I}_{\mathrm{df}}\right)$ for an all-black Eppley Precision Spectral Pyranometer (PSP) under clear-sky conditions. However, there have been issues identified with the site-dependent thermal offsets in all-black thermopile pyranometer measurements (Gulbrandsen. 1978; Dutton et al., 2000). Therefore, the uncertainty in the reference diffuse-sky radiation is actually $\pm 2.5 \%+$ $\mathrm{W}_{\text {off, }}$ where $\mathrm{W}_{\text {off }}$ is a thermal offset in watts per square meter. $\mathrm{W}_{\text {off }}$ for the NREL site has been characterized to be about $20 \mathrm{~W} / \mathrm{m}^{2}$.

The reference global irradiance is computed from an absolute-cavity pyrheliometer measurement of the direct-beam radiation, $\mathrm{I}_{\mathrm{dn}}$, multiplied by the cosine of the zenith angle, plus the diffuse-sky radiation, $\mathrm{I}_{\mathrm{df}}$. Each individual pyranometer signal, $\mathrm{Vu}$, is then divided by the reference irradiance to produce the individual pyranometer responsivity:

$$
R s=\frac{V u}{I_{d n} \bullet \operatorname{Cos}(z)+I_{d f}} .
$$


NREL has previously published a detailed uncertainty analysis for the calibration of thermopile pyranometers and pyrheliometers (Myers, 1988). The uncertainties derived for pyrheliometer and pyranometer calibrations derived in that report were $2.0 \%$ for pyrheliometers and $2.8 \%$ for pyranometers. These uncertainties were associated with the determination of a single responsivity number for use under all zenith angles and sky conditions, for an "average" radiometer with cosine, azimuthal, and thermal bias-error sources of $1.0 \%$ each and random error sources of $0.5 \%$ each, respectively.

Recent research within the DOE ARM program, NASA EOS Validation Program, WMO BSRN project, and NOAA SRRB projects has revealed several sources of uncertainty, particularly the thermal offset bias errors in both calibration techniques that were not accounted for in the previous analysis.

The NREL broadband shortwave pyranometer calibration process is implemented in a suite of hardware and software we call Radiometer Calibration and Characterization, or RCC. We have incorporated revisions to the RCC software and hardware to address the issues of thermal offsets in all-black pyranometer detectors and non-uniform geometrical (azimuthal and cosine) responses. These revisions should improve the BORCAL process, including the computation of uncertainties.

\subsection{Radiometer Calibration and Characterization (RCC)}

RCC software and hardware were developed to efficiently manage the calibration, on an annual basis, of hundreds of pyranometers used in DOE PV research and development and climate research programs. RCC produces calibration results (instrument responsivities) and includes database management tools for maintaining an historical database of instrument responsivities. The rest of this section will deal only with the technical improvements in determining pyranometer responsivities.

The RCC software requires a rigorous configuration and setup session for installing and checking the operation of all equipment and sensors, including the reference cavity radiometer and diffuse measuring pyranometers. In addition to the reference (direct and diffuse) and test (pyranometer, pyrheliometer) sensors, RCC requires a set of "control" instruments that are included in every calibration to monitor the process stability. Also required are silicon photodiode global and direct-beam irradiance measurements for determining irradiance stability. The atmospheric stability radiometer (ASR) units are sampled 60 times a minute, and instability is reported by flagging the data and alerting the operator. In addition, meteorological data for temperature and relative humidity are recorded, from which atmospheric broadband turbidity is estimated using algorithms derived at NREL (Maxwell and Myers, 1992; Myers and Maxwell, 1992). Various conditions set alarms and flag suspect data. These include:

Ref and ASR Mismatch Alarm: A mismatch of more than $18 \%$ exists between ASR and Ref irradiances. 
REF Alarm: A mismatch is detected between multiple reference instruments (a difference of $1 \%$ between multiple cavity radiometers, or $6 \%$ between two diffuse pyranometers).

TST Alarm: A difference of more than $0.5 \%$ has occurred between adjacent responsivities for a single instrument.

STD Alarm: A mismatch of more than $6 \%$ exists between the irradiance reported by the reference instruments and a standard control instrument (pyranometer and pyrheliometer included in every calibration event as control units).

MET Alarm: Adjacent (i.e., between the sample period set for collecting data, usually 30 seconds, but can be varied by the user) readings of meteorological instruments differ by more than $3^{\circ} \mathrm{C}$ for temperature, or $7 \%$ in Relative Humidity.

\subsection{Diffuse Irradiance and Thermal Offsets}

Thermopile-based pyranometers rely on the temperature difference between junctions of dissimilar metals in contact with a surface that absorbs solar radiation ("hot" junctions) and reference, or "cold" junctions, which do not receive any solar radiation. There are two widely available types of thermopile-based pyranometers for measuring diffuse-sky radiation under a tracking shading disk. The first has the "hot" junctions in contact with a black absorbing receiver, with "cold" or reference junctions inside the radiometer, and not exposed to the radiant energy. In Figure 2.5, the top unit, an Eppley Laboratory Model PSP is an example of these "all-black" sensor pyranometers. The second type of thermopile has the "hot" junctions again in contact with a black absorbing surface, but the reference "cold" junctions are under a white, reflective surface that absorbs very little shortwave solar radiation. The bottom instrument in Figure 2.5 is an example of the latter, an Eppley Laboratory Model 8-48 "black-and-white" unit.

Pyranometers with all-black receivers are rarely in thermal equilibrium when deployed outdoors. Thermal infrared (IR) energy is exchanged between the absorbing sensor, dome, and sky. A different regime of IR exchanges takes place between the cold junctions, the body of the instrument, and the atmosphere (Dutton et al., 2000; Gulbrandsen, 1978). These exchanges result in a net negative thermal offset in the thermopile voltage signal. These offsets are seen in nighttime data, which are always negative and from 5 to $25 \mathrm{~W} / \mathrm{m}^{2}$ in magnitude.

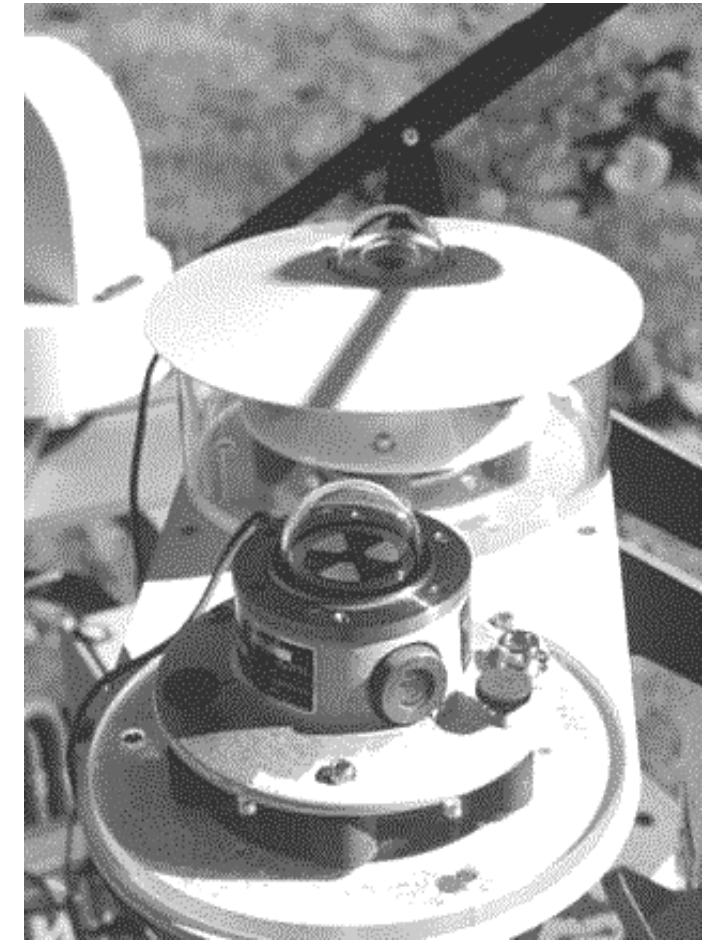

Figure 2.5. All-black (top unit) and black-and-white thermopile pyranometers under tracking shading disks. 
Black-and-white pyranometers have a much smaller thermal offset, because both the hot and cold junctions see the same dome and sky thermal radiation. Figure 7 shows an example of clear-sky diffuse irradiance measured with an all-black (PSP) detector (lower line) and a black-and-white detector (upper line) at NREL. The $20 \mathrm{~W} / \mathrm{m}^{2}$ difference between the two instruments is due to the thermal offset in the shaded all-black instrument. This difference is approximately constant for clear-sky conditions throughout the year, and it is the value of $\mathrm{W}_{\text {off }}$ used for all-black pyranometers in the following section on uncertainty. The $\mathrm{W}_{\text {off }}$ for the black-and-white units is about $2 \mathrm{~W} / \mathrm{m}^{2}$, based on nighttime data and experiments with capping the radiometers in bright sunlight.

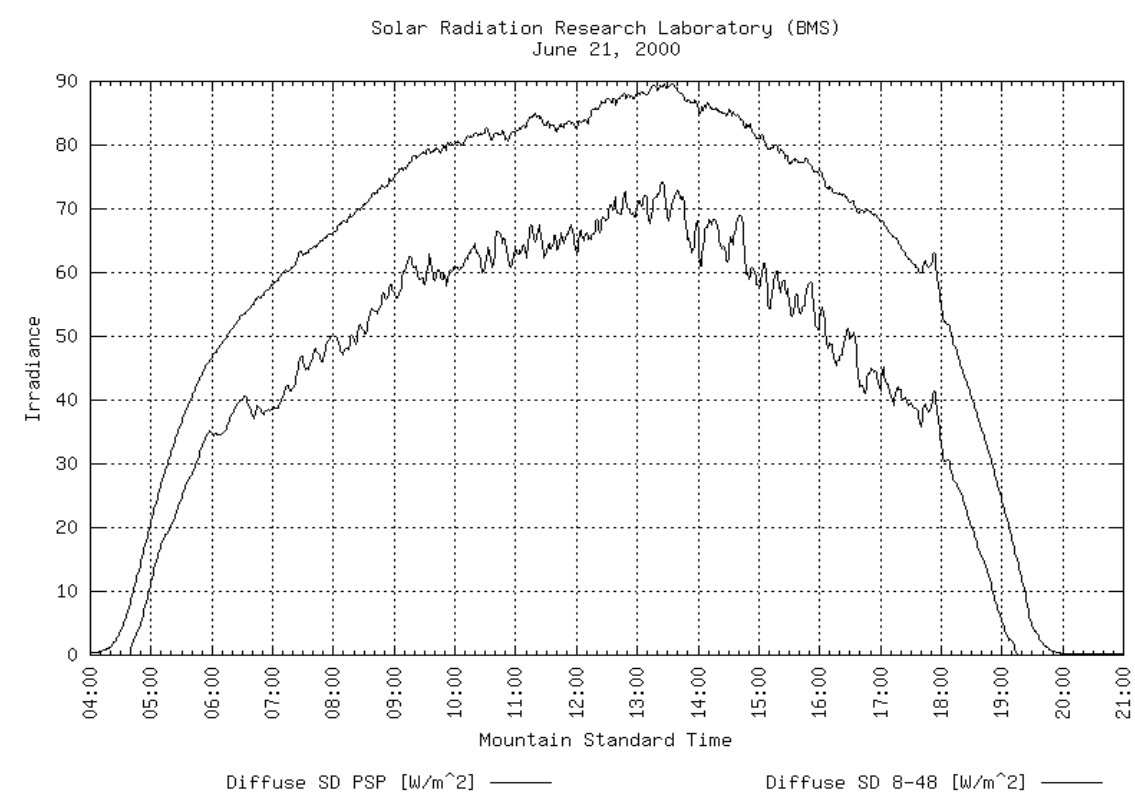

Figure 2.6. Clear-sky diffuse irradiance under tracking shading disks for an allblack (lower line) and black-and-white (upper line) pyranometers.

\subsection{RCC Reporting}

RCC reports include a great deal of information to help the Measurements and Characterization Team and the user evaluate the quality of the BORCAL process and interpret the results of the calibrations. In addition to the individual calibration results, discussed below, RCC generates a time-series plot of the direct-normal irradiance measured by the cavity pyrheliometer and the diffuse-sky irradiance, as well as the computed reference global irradiance. See Figure 2.7. Also shown in the bottom panel of Figure 2.7 is the ratio of the diffuse-sky irradiance to the computed reference global irradiance. This ratio indicates the relative contribution of the diffuse irradiance (and errors in its measurement) to the total reference irradiance.

Another set of time-series plots of use in interpreting the calibration results are plots of the estimated atmospheric turbidity, mentioned in Section 2.2, and the relative humidity and ambient temperature. Figure 2.8 is an example of the plots for these parameters in the top, middle, and bottom panels, respectively. 


\section{Reference Irradiance}
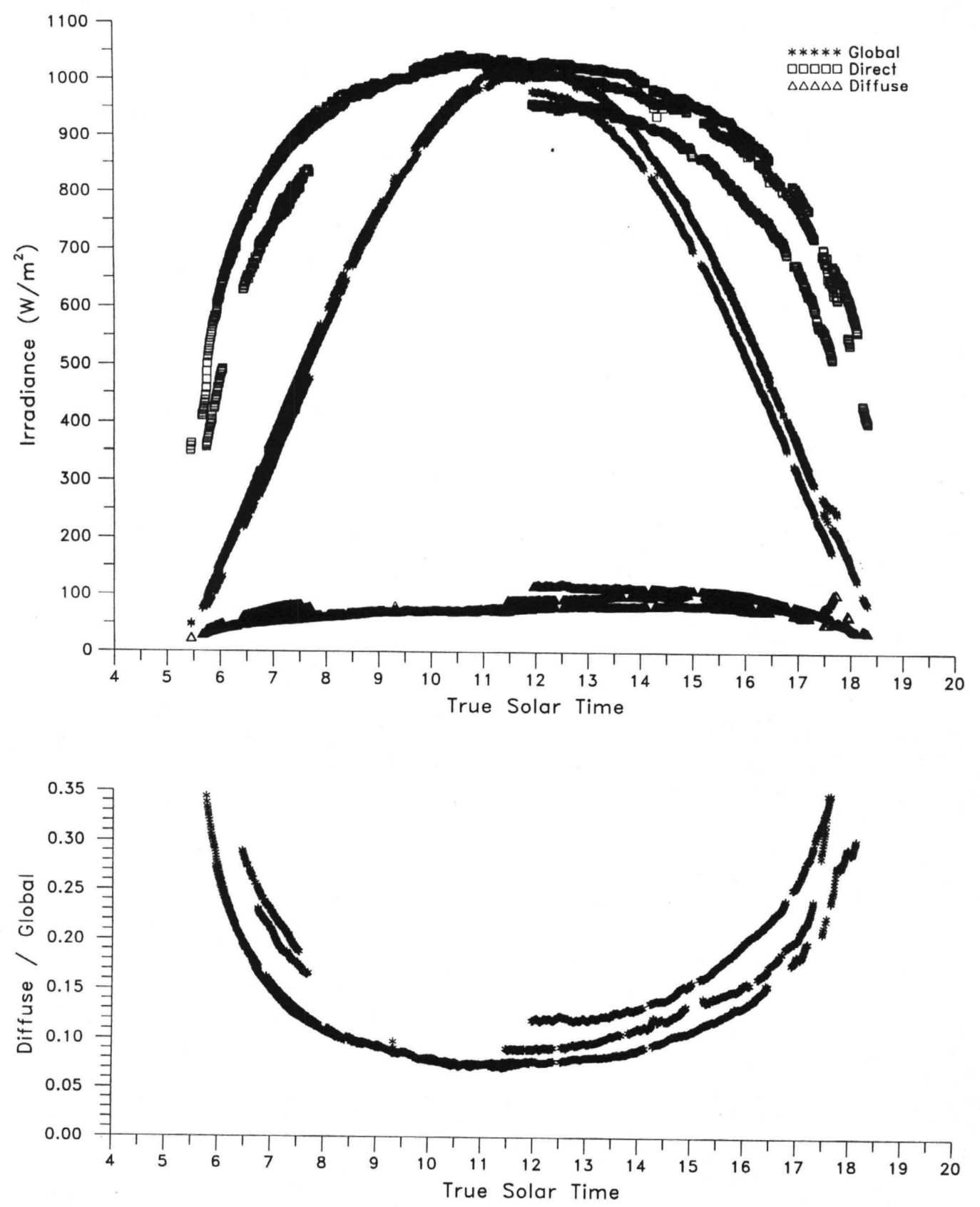

Figure 2.7. Reference global irradiance and direct and diffuse components from which it was computed (top panel). Ratio of diffuse-sky irradiance to total global reference irradiance (bottom panel). 

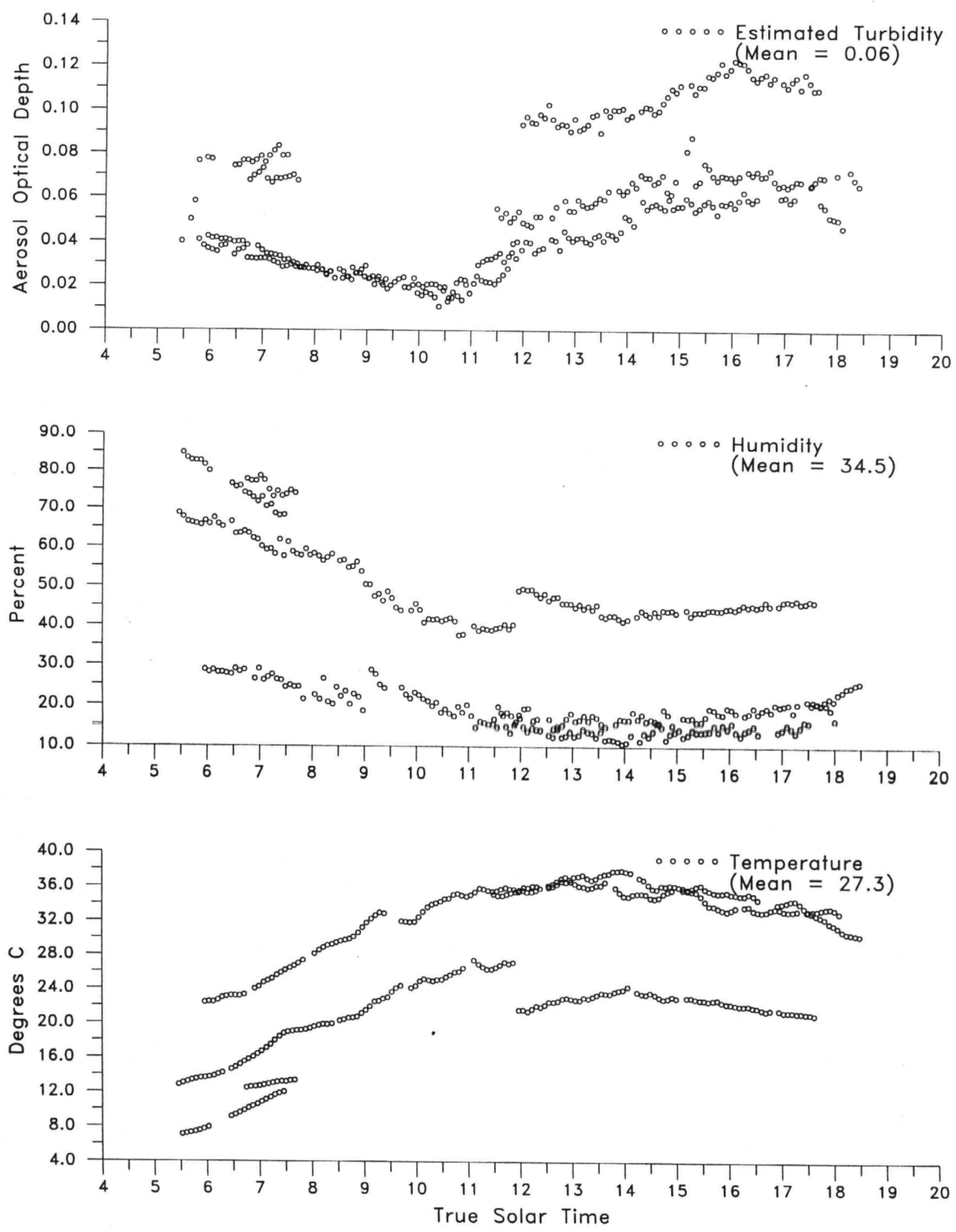

\section{BORCAL 2000-01 Meteorological Observations}

Figure 2.8. Meteorological observations recorded during RCC/BORCAL data collection. Aerosol optical depth or turbidity (top panel), relative humidity (middle panel), and ambient temperature (bottom panel). Conditions on four different days are identifiable. 
RCC records all of the information needed to report how each pyranometer responds with respect to the zenith angle, or incidence angle. A perfect pyranometer, with a "lambertian" receiving surface, would show no variation, or constant responsivity as a function of zenith angle. Figure 2.7 shows a plot of the variation in responsivity with zenith angle for an Eplab PSP, also known as the "cosine response". Note that each instrument has its own distinctive individual cosine response; there is not a "typical" cosine response curve for various makes and models of pyranometers.

$31548 F 3$

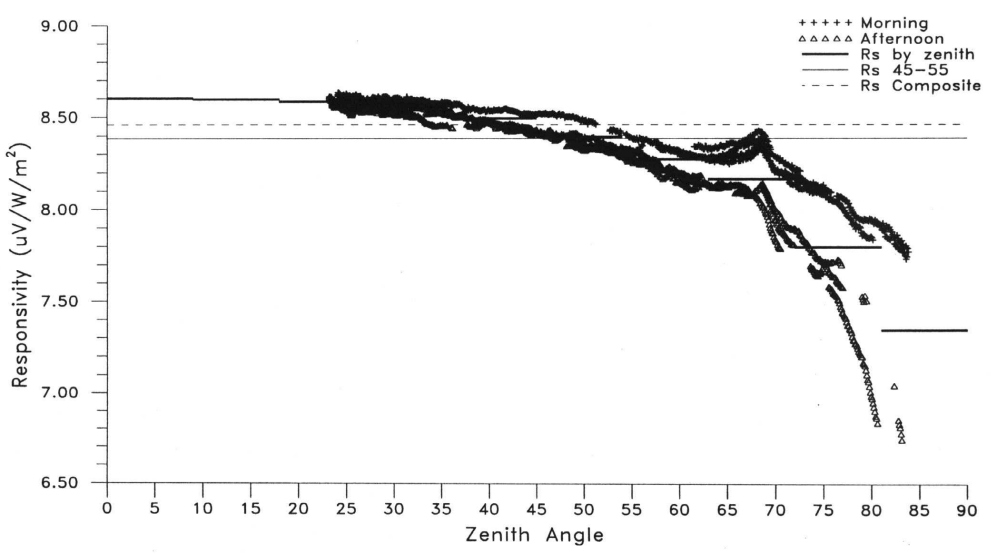

Figure 2.9. Pyranometer cosine response curve generated by RCC. Morning data is "top" leg, afternoon data the "bottom" leg. Horizontal bars are mean responsivity in zenith angle ranges spanned by the bars.

RCC computes the mean response with each of ten zenith angle bins, each $9^{\circ}$ wide, from $0^{\circ}$ to $90^{\circ}$ and reports the results, as shown in Table 2.1 .

Table 2.1. RCC report of mean pyranometer responsivity within zenith angle bins

\begin{tabular}{lccc}
\hline Bin & Rs & Unc & Pct \\
\hline 45-55 & 8.262 & 0.18 & 2.2 \\
Composite & 8.328 & 0.45 & 5.4 \\
Zen 00-09 & 8.406 & 0.18 & 2.1 \\
Zen 09-18 & 8.408 & 0.17 & 2.0 \\
Zen 18-27 & 8.387 & 0.18 & 2.1 \\
Zen 27-36 & 8.353 & 0.19 & 2.2 \\
Zen 36-45 & 8.314 & 0.20 & 2.4 \\
Zen 45-54 & 8.265 & 0.18 & 2.2 \\
Zen 54-63 & 8.214 & 0.18 & 2.2 \\
Zen 63-72 & 8.208 & 0.25 & 3.0 \\
Zen 72-81 & 8.118 & 0.28 & 3.4 \\
Zen 81-90 & 7.972 & 0.27 & 3.3 \\
\end{tabular}

Bin $=$ Zenith angle bin identifier

Rs $=$ Mean responsivity within bin (both morning and afternoon data) $\mu \mathrm{V} / \mathrm{W} / \mathrm{m}^{2}$

Unc $=$ Uncertainty in units of Rs $\left(\mu \mathrm{V} / \mathrm{W} / \mathrm{m}^{2}\right)$ 
Pct $=$ Uncertainty as a percent of mean responsivity (percent)

(see Section 2.5 for discussion of uncertainty)

45-55 $=$ Bin for computing responsivity under isotropic conditions

Composite $=\operatorname{Cos}(Z)$ weighted mean responsivity.

The mean responsivity in each Z-bin is plotted as a horizontal bar, as shown in Figure 2.9. The 45-55 and cosine weighted composite responsivities are plotted as horizontal lines spanning the total zenith angle range.

The 45-55 bin represents an average responsivity for homogenous, isotropic sky conditions. The "composite" result is computed as the average of all responsivities weighted by the cosine of Z. Typically, data can be collected using one or the other of these latter responsivities; however, the most accurate determination of the total global irradiance is accomplished by using the responsivity as a function of zenith (incidence) angle of the direct beam. See Section 2.6 for more details.

\subsection{RCC Uncertainty}

As a result of implementing a more accurate computation of solar zenith angles and measurement of diffuse-sky irradiance, our estimates of uncertainty based on earlier BORCAL procedures and instrumentation must be revised. The "base uncertainty" of $1.3 \%$ used previously for the reference irradiance calculation for pyranometers is now reduced by a factor of about 2 . A detailed uncertainty analysis and new prescription for computing the uncertainty for subsequent BORCAL events are described below. The new methods will be incorporated into subsequent RCC versions.

\subsubsection{Data Acquisition}

RCC uses hardware comprising a Fluke Helios Plus 2287A data logger, with a highperformance Analog-to-Digital (A /D) converter, and Isothermal voltage input cards. The one year accuracy specification for this configuration on the DC voltage range used $( \pm 64$ $\mathrm{mV}$ ) is $0.03 \%$ of reading +9 microvolts $(\mu \mathrm{V})$ (Fluke, 1990). NREL tests the "zero" input voltage level, measured by putting a high-quality short circuit between the high and low terminals, and the $9 \mu \mathrm{V}$ offset is typical. For a nominal $10 \mathrm{mV}(=10,000 \mu \mathrm{V})$ thermopile pyranometer signal, this amounts to $9+3=12 \mu \mathrm{V} / 10000 \mu \mathrm{V}$ or $0.12 \%$ for data logger contributions to measurement uncertainty.

\subsubsection{Transfer of World Radiometric Reference (WRR)}

The WRR is transferred with an uncertainty of $0.3 \%$ from the World Standard Group (WSG) of absolute cavity radiometers to an NREL reference group of cavity radiometers (Technical Measurements Incorporated [TMI] 68018, AHF 29220, and AHF 30713) at the World Radiation Center (WRC) at Davos, Switzerland, every five years (beginning in 1980). NREL has documented the transfer process in Reda (1996). NREL transfers the WRR to working reference cavity radiometers during "NREL Pyrheliometer Comparisons" (Reda et al., 1996; 1997; 1998; 1999). Root-sum-squaring the $0.3 \%$ uncertainty in WRR from the reference cavity and $0.2 \%$ random variation in the transfer 
of WRR to the working reference AHF 31104 result in the overall uncertainty in the direct-beam irradiance of $0.35 \%$. The correction factor to reduce AHF 31104 measured irradiance to WWR is $1.0002 \pm 0.35 \%$.

\subsubsection{Zenith-Angle Computation}

Additional uncertainty in the reference irradiance for pyranometers is due to computing the solar zenith angle, $\operatorname{Cos}(Z)$. This computation depends on knowledge of the latitude, longitude, local standard time, solar equation of time (difference between True Solar Time and Local Standard Time), and solar declination (the angle between the center of the solar disk and the projection of the Earth's equator on the sky dome) (Iqbal, 1983). NREL determined the location of our BORCAL calibration platform to within $0.0001^{\circ}$, or \pm 30 feet, using Global Positioning System (GPS) measurements. The GPS measurements agree to within the $0.0001^{\circ}$ GPS accuracy with our previous position information. RCC software resets the local standard time, again using GPS timecodes, to within \pm 1 second. The current version of RCC uses the algorithm of Michalsky (Michalsky 1998a; 1998b), accurate to within $0.01^{\circ}$ in $Z$. For $Z$ less than $75^{\circ}$, the uncertainty in $\operatorname{Cos}(Z)$ is less than $0.06 \%$. For $Z$ greater than $75^{\circ}$, an atmospheric refraction correction is applied (Zimmerman, 1981) to compute an effective zenith angle to an accuracy of $0.02^{\circ}$. The resulting $0.03^{\circ}$ uncertainty in $Z=85^{\circ}$ produces a $0.6 \%$ uncertainty in $\operatorname{Cos}(Z)$, growing to $3 \%$ at $\mathrm{Z}=89^{\circ}$.

\subsubsection{Reference Diffuse-Sky Irradiance}

NREL characterizes the responsivity of the pyranometer used to measure the diffuse-sky radiation as the mean of the responsivities at $Z=45^{\circ}$ in three azimuth directions $\left(0^{\circ}, 120^{\circ}\right.$, and $240^{\circ}$ ) with respect to south $=0^{\circ}$. A detailed uncertainty analysis of this refined approach (Reda and Myers, 1999) results in a total uncertainty of $2.5 \%$ of reading in the calibration factor for measuring total diffuse-sky irradiance $\left(\mathrm{I}_{\mathrm{df}}\right)$ for pyranometers under clear-sky conditions. Site-dependent thermal offsets in all-black thermopile pyranometer

measurements have been identified by Gulbrandsen (1978) and Dutton et al. (2000). The uncertainty in the reference diffuse is actually $\pm 2.5 \%$ of reading $+\mathrm{W}_{\text {off }}$, where $\mathrm{W}_{\text {off }}$ is a thermal offset in watts per square meter. $\mathrm{W}_{\text {off }}$ for PSPs at the NREL site has been characterized to be about $-20 \mathrm{~W} / \mathrm{m}^{2}$. The thermal offset in a black-and-white (model 8-48) pyranometer is no more than $-2 \mathrm{~W} / \mathrm{m}^{2}$, but the uncertainty in determining the responsivity at $45^{\circ}$ is still on the order of $2.5 \%$ of reading.

\subsubsection{Total Uncertainty Calculation}

Summing the uncertainty from the data logger $(0.12 \%)$, WRR and transfer of WRR $(0.35 \%)$, and cosine of the zenith angle $\left(0.06 \%\right.$ for $\left.\mathrm{z}<75^{\circ}\right)$ uncertainty in the computation of the vertical component of the direct beam is $0.53 \%$. For a typical clear-sky diffuse irradiance of $100 \mathrm{~W} / \mathrm{m}^{2}$, measured with an all-black detector pyranometer, the uncertainty in the diffuse component of the reference irradiance is $\pm 2.5 \%$ of reading $+20 \mathrm{~W} / \mathrm{m}^{2}$, or $\pm 2.5 \mathrm{~W} / \mathrm{m}^{2}+20 \mathrm{~W} / \mathrm{m}^{2}=22.5 \mathrm{~W} / \mathrm{m}^{2}$. Using the black-and-white pyranometer, the uncertainty in the diffuse is $\pm 2.5 \%$ of reading $+2 \mathrm{~W} / \mathrm{m}^{2}=2.5 \mathrm{~W}+2 \mathrm{~W} / \mathrm{m}^{2}=4.5 \mathrm{~W} / \mathrm{m}^{2}$, or $0.50 \%$ of the reference irradiance. 
Using a pyranometer with an all-black detector to measure diffuse, assuming a clear-sky global irradiance of $900 \mathrm{~W} / \mathrm{m}^{2}$, with a diffuse component of $100 \mathrm{~W} / \mathrm{m}^{2}$, the $22.5 \mathrm{~W} / \mathrm{m}^{2}$ diffuse uncertainty is $22.5 / 900=2.5 \%$. Combining the diffuse uncertainty with the $0.53 \%$ direct-beam uncertainty by root-sum-squaring, the total "base" uncertainty in the determination of a single responsivity measurement using an all-black detector for the diffuse-sky irradiance, for $\mathrm{Z}<70^{\circ}$, before adding in variability in each instrument is:

$$
U_{t o t}=\sqrt{0.53^{2}+2.5^{2}}=2.6 \% \text {. }
$$

Using a pyranometer with a black-and-white sensor for the diffuse-sky irradiance, the uncertainty in the diffuse (as a percentage of the total reference irradiance) is $0.50 \%$, and the "base" total uncertainty in each individual responsivity for $\mathrm{Z}<70^{\circ}$ is reduced to:

$$
U_{t o t}=\sqrt{0.53^{2}+0.50^{2}}=0.73 \% \text {. }
$$

Because the uncertainty, $U_{i}$, for each individual responsivity, Rs, is a function of the zenith angle and the magnitude of the diffuse irradiance, RCC computes the uncertainty for each individual Rs using:

$$
\begin{aligned}
& U_{d n}=0.53 \% \\
& U_{Z}=100 \bullet \frac{\left(\operatorname{Cos}(Z)-\operatorname{Cos}\left(Z+0.03^{\circ}\right)\right)}{\operatorname{Cos}(Z)} \% \\
& U_{d f}=100 \bullet \frac{\left(2+0.025 \bullet I_{d f}\right)}{\left(I_{d n} \bullet \operatorname{Cos}(Z)+I_{d f}\right)} \% \\
& U_{i}=\sqrt{U_{d n}^{2}+U_{Z}^{2}+U_{d f}^{2}} \% .
\end{aligned}
$$

After each of the ten zenith-angle bins is completed, the mean responsivity, $\overline{\mathrm{R}}_{\mathrm{s} \text {. }}$ for the ten $\left(9^{\circ}\right.$ wide) zenith-angle bins is computed. The total uncertainty for the mean responsivity, $\mathrm{U}_{\mathrm{Rs}}$, in each bin is the root-sum-square of the mean of the $\mathrm{U}_{\mathrm{i}}, \bar{U}_{i}$, and one-half of the range (maximum - minimum), $\mathrm{R}$, as a percentage of the mean $\mathrm{R}_{\mathrm{s}}$ for the bin. The range term reflects the fact that for the same zenith-angle bins, morning and afternoon responsivities may not overlap, as shown in Figure 2.9.

$$
U_{R s}=\sqrt{\bar{U}_{i}^{2}+\left(100 \bullet 0.5 \bullet \frac{R}{\bar{R}_{s}}\right)^{2}}
$$

For computing the uncertainty in the determination of the responsivities of pyrheliometers, the sum of data-logger and absolute-cavity radiometer uncertainty is $0.47 \%$ (no zenith-angle term). After the mean responsivity, $\mathrm{R}_{\mathrm{s}}$, and the range, $\mathrm{R}$, 
(maximum - minimum) as a percentage of the mean are computed, the uncertainty in Rs, $\mathrm{U}_{\mathrm{Rs}}$ is computed as

$$
U_{R s}=\sqrt{(0.47)^{2}+\left(100 \bullet 0.5 \bullet \frac{R}{\bar{R}_{S}}\right)^{2}} .
$$

\subsection{Results and Impact of RCC/BORCAL Revisions}

The above-described improvements in RCC/BORCAL operations and procedures have the following specific impacts:

(1) Measurements of clear-sky total global solar radiation made with pyranometers calibrated at NREL before March 2000 are about 2.5\% to 3\% (of reading) too low. This amounts to $25 \mathrm{~W} / \mathrm{m}^{2}$ to $30 \mathrm{~W} / \mathrm{m}^{2}$ at "l-sun" of $1000 \mathrm{~W} / \mathrm{m}^{2}$.

(2) Absolute uncertainty in responsivities of pyranometers and pyrheliometers has been reduced by about $15 \%$.

(3) Absolute accuracy of total global pyranometer measurements has been improved by removing a negative bias (due to thermal offsets in all-black pyranometers measuring the diffuse-sky irradiance) of about $20 \mathrm{~W} / \mathrm{m}^{2}$ in the calibration reference irradiance during calibrations at NREL/SRRL.

(4) Total global pyranometer measurements made using previous versions of BORCAL/RCC, or any component summation technique method using an all-black pyranometer for diffuse-sky measurements, have an inherent negative bias (about 20 $\mathrm{W} / \mathrm{m}^{2}$ at NREL) built into the derived responsivity, and hence, in the measured data.

(5) All-black pyranometers (which do not have a compensating thermopile ) calibrated as described in (3) above, and used to measure diffuse-sky radiation, will still have inherent thermal offsets on the order of $20 \mathrm{~W} / \mathrm{m}^{2}$ that must be accounted (corrected) for.

Regarding (5) above, the all-black detector pyranometers that do not have a compensating thermopile (Eplab Precision Spectral Pyranometer) need to have the thermal offset added back in to get correct diffuse-sky radiation. This is because the thermal offsets result from the shading configuration. Even though the radiometer was calibrated against a reference irradiance with no thermal offset, the thermal offset still occurs in the measurement configuration.

\subsection{Applying Responsivity as a Function of Zenith Angle}

Whether calibrated with all-black or black-and-white pyranometers for the reference irradiance diffuse during RCC/BORCAL, the most accurate determination of the total global irradiance is accomplished by using the responsivity as a function of zenith (incidence) angle of the direct beam. Most of these corrections for zenith angles less than 
$70^{\circ}$ are less than $3 \%$ of reading; and they increase to about $15 \%$ of reading at lower zenith angles.

Figure 3.1 shows that applying zenith-angle corrections for a specific pyranometer reduces the difference between the most accurate measurement of the global irradiance from $40 \mathrm{~W} / \mathrm{m}^{2}$ to less than $15 \mathrm{~W} / \mathrm{m}^{2}$ (a $37 \%$ reduction in the error). The more accurate irradiance is computed using a pyrheliometer to measure the direct beam and a black-andwhite pyranometer under a tracking shading disk. To correct the measured global pyranometer data, it was multiplied by the ratio of the single calibration factor used to collect the data, to the calibration factor derived from the appropriate zenith-angle responsivity bin.

Because irradiance levels under cloudy skies are usually much lower than the irradiances under cloudy conditions, applying the zenith-angle corrections results in much smaller changes in terms of $\mathrm{W} / \mathrm{m}^{2}$ than for clear skies. Therefore, the zenith-angle corrections can be applied uniformly, no matter what the sky conditions.

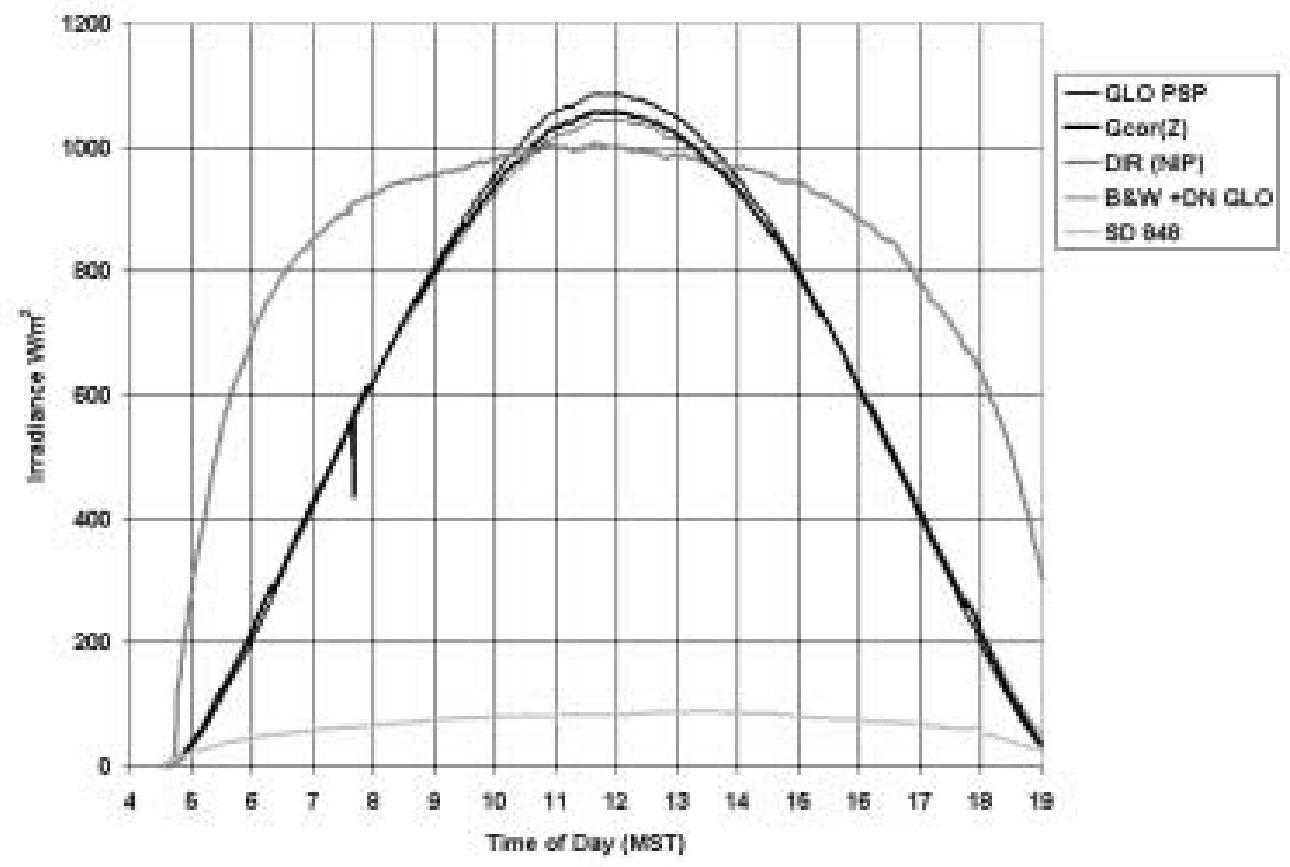

Figure 3.1. Reducing absolute error in measured pyranometer global irradiance (GLO PSP) using zenith-angle corrections. Top black curve is measured global irradiance using single (45-55 bin) responsivity. The next curve down (thick black line, Gcor(Z)) is the measured global irradiance after correcting the measured data with responsivity for the appropriate zenith-angle bin. The third line down (thin gray line, B\&W+DN GLO) is the global irradiance computed from a pyrheliometer and black-and-white shaded pyranometer. Thick gray line (fourth from top) is the pyrheliometer data (DIR (NIP)), and the gray line at the bottom is the shaded black-and-white pyranometer diffuse (SD 848). 
Figure 3.2 shows the solar irradiance data for a partly cloudy day (June 19, 2000). We applied the zenith-angle bin responsivities to the measured global irradiance data, as in Figure 3.1. The mean difference between measured and computed global irradiance is 8 $\mathrm{W} / \mathrm{m}^{2}$. After applying zenith-angle bin responsivities, the mean difference is $6 \mathrm{~W} / \mathrm{m}^{2}$. Differences between corrected and uncorrected data are only barely discernable in the clear-sky portion of the data before 9 A.M. During the rest of the day, where global irradiances are less than $500 \mathrm{~W} / \mathrm{m}^{2}$, the corrections result in relatively small $\left(1\right.$ to $\left.5 \mathrm{~W} / \mathrm{m}^{2}\right)$ differences between the measured and corrected data. Indeed, both the measured and corrected global irradiance is usually within $10 \mathrm{~W} / \mathrm{m}^{2}$ of the irradiance computed from the direct-beam and shaded black-and-white pyranometer.

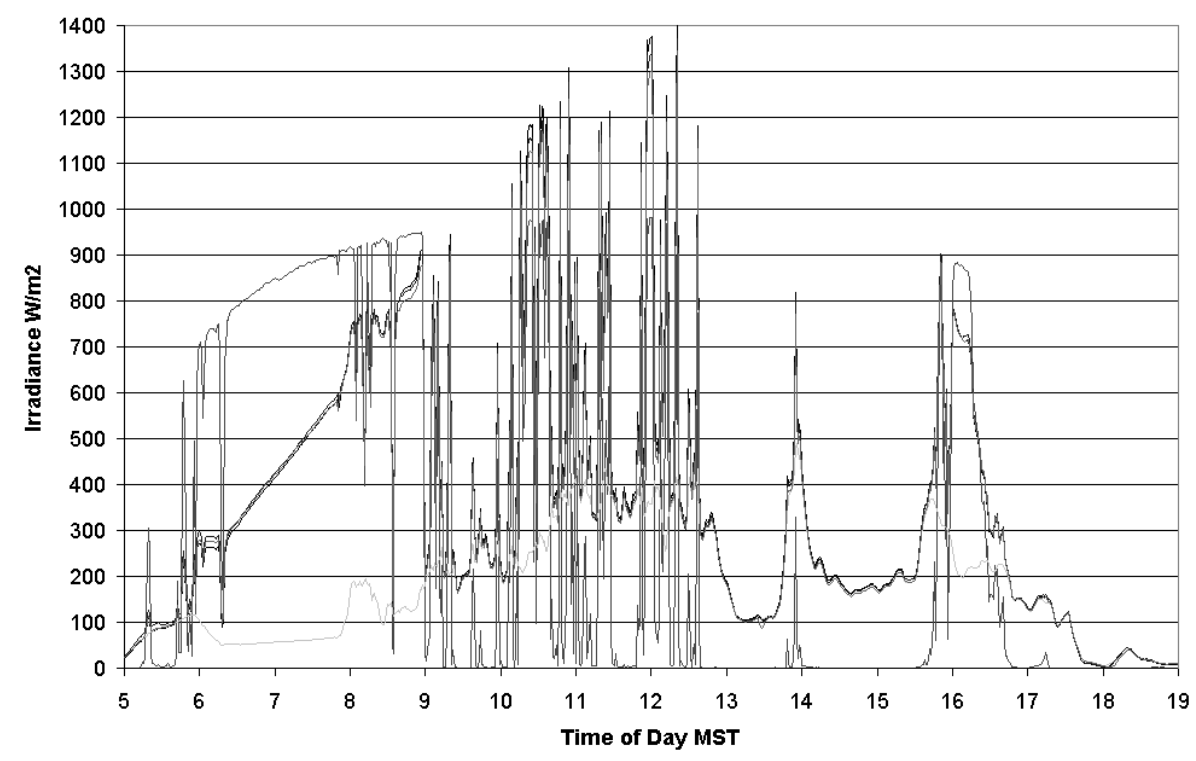

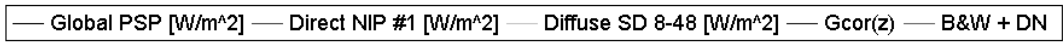

Figure 3.2. Partly cloudy day (June 19, 2000) example for applying zenith-angle bin responsivities to measured global total irradiance for the same pyranometer as in Figure 3.1. Shaded black-and-white diffuse-sky is very light gray line at bottom. Differences between corrected and uncorrected data are only barely discernable in the clear-sky data before 9 A.M.

\subsection{Spectral Distribution of Pulsed Solar Simulators}

Pulsed or "flash" solar simulators, as shown in Figure 4.1, are commercially available and are widely used in photovoltaic production lines to produce "standard reporting conditions" reports on production modules. Xenon-arc lamps are used to produce a pulse of light with a duration of 1 millisecond (ms) to several tens of ms. Figure 4.2 is a typical flash profile. 


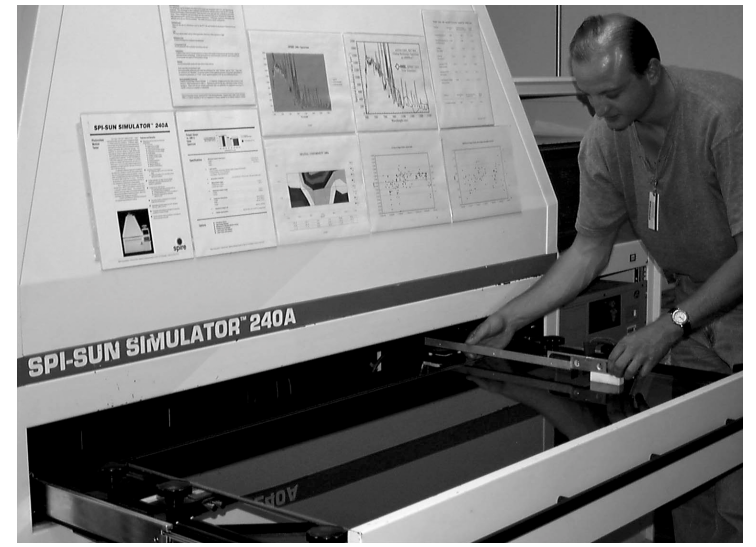

Figure 4.1. Commercial solar simulator for photovoltaic testing and research.

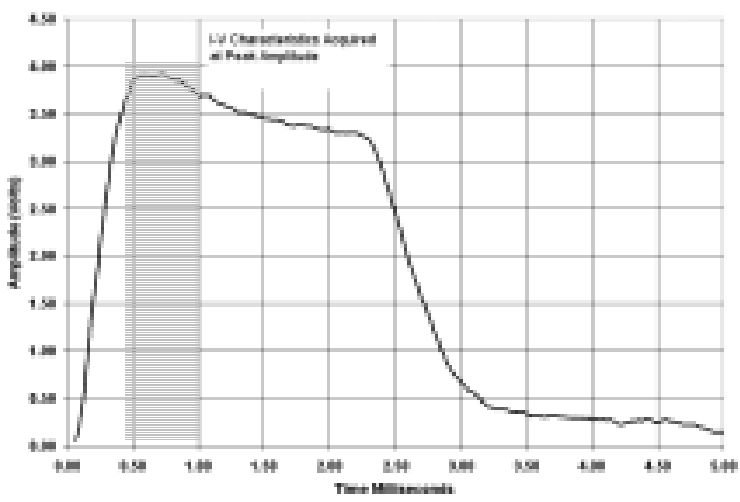

Figure 4.2 Pulse simulator flash amplitude versus time. Current-voltage sweep occurs in shaded interval.

These simulators are also used for research purposes to evaluate the performance of various PV technologies and to determine coefficients of current and voltage as a function of temperature or irradiance. Programmable electronic loads sweep the voltage and current regime of the device under test from open-circuit to short-circuit conditions, producing the current-voltage, or I-V, characteristics of the device. Pulse simulators are used in lieu of continuous simulators because much lower average power is required and the device does not increase in temperature due to prolonged exposure to the light.

The lamps and associated optical filters and electronic systems are designed to produce a pulse with the intensity and spectral distribution of natural solar radiation specified in the ASTM standards for so-called "reference" spectra. There are two ASTM reference spectra, one for total global-hemispherical solar radiation on a $37^{\circ}$ south-facing tilted surface (ASTM E-891) and one for direct-normal radiation solar radiation (ASTM E892). Most of the solar simulators on the market attempt to match the globalhemispherical spectrum. Figure 4.3 plots the two reference spectra magnitude in watts per square meter per micrometer of passband from 0.3 micrometers $(\mu \mathrm{m})$ or 300 nanometers (nm) to $4.3 \mu \mathrm{m}$ or $4300 \mathrm{~nm}$. 


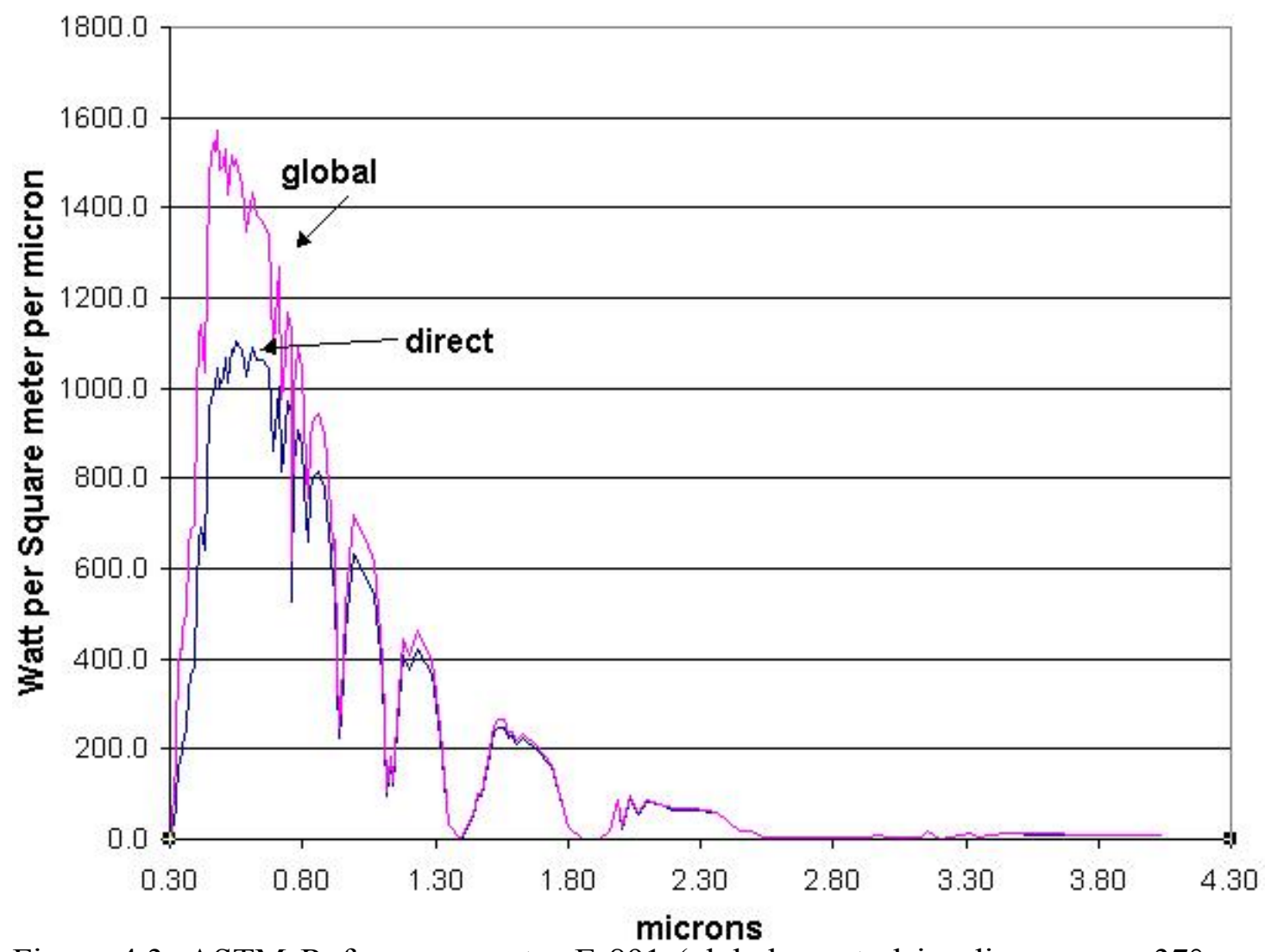

Figure 4.3. ASTM Reference spectra E-891 (global spectral irradiance on a $37^{\circ}$ southfacing tilted surface at Air Mass 1.5) and E-892 (Air Mass 1.5 direct-normal spectral irradiance). Atmospheric conditions are specified as visibility of $23 \mathrm{~km}$, aerosol optical depth of 0.27 , total precipitable water of $1.42 \mathrm{~cm}$, and total column ozone of $0.34 \mathrm{~cm}$.

ASTM standard practice E-927 (ASTM 1994) describes a rating system for evaluating the classification of solar simulators with respect to the degree the lamp spectrum matches the reference spectrum. A measurement of the spectral distribution of the flash simulators is necessary to determine the quantitative difference between the simulator spectral distribution and either the reference spectrum (resulting in a classification of the quality of the simulator) or natural solar spectral distributions obtained during outdoor testing. For reasonable comparisons between PV technologies of widely varying spectral response regimes, a method of computing the spectral mismatch correction factors is prescribed in ASTM E-973M (ASTM 1998) that requires measured spectral data as well.

The Measurements and Instrumentation Team has developed several approaches to measure the spectral distribution of our pulsed solar simulators. The methods are described below, as well as our estimates of uncertainty and results on monitoring the temporal changes in spectral distributions over many months. 


\subsection{Pulse Analysis Spectrometer System (PASS)}

The most powerful and accurate system developed by the Measurements and Instrumentation Team is the Pulse Analysis Spectroradiometer System (PASS). The PASS system consists of an Optronic Laboratories OL-746 scanning grating monochromator with silicon, germanium, and lead sulfide detectors, integrating-sphere input optics, an external pulse generator for triggering data collection, a digital oscilloscope for capturing the entire light pulse (at the single wavelength set on the monochromator) as a function of time, and a computer program to control, calibrate, acquire measurement data, and apply the calibration functions to produce the spectral irradiance data and save it in a digital file. The equipment is shown in Figure 4.4.

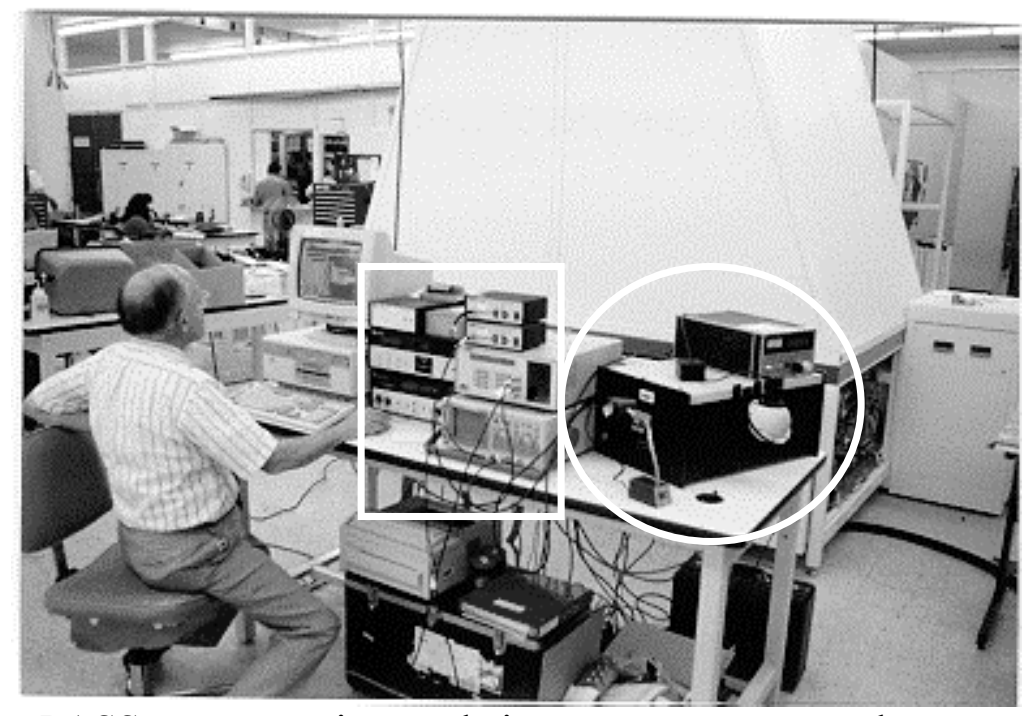

Figure 4.4. The PASS system equipment being set up to measure the spectral distribution of a pulse solar simulator. Left to right: control computer, monochromator interface, amplifiers, pulse generator, digital oscilloscope (box), and monochromator (circle).

The PASS is capable of sampling the lamp pulse at any location within the period of the pulse (i.e., at any amplitude within the pulse) or over any short period within the pulse. The monochromator (circle) is placed inside the simulator under the lamp with the integrating-sphere aperture near the test plane, and the simulator is set to run continuously. The lamp flash triggers the control electronics (box) to digitize the pulse. The computer then imports the digitized pulse and integrates the curve between boundaries set by the user. A calibration file based on a chopped signal from a 1000-watt standard of spectral irradiance lamp, traceable to the National Institute of Standards and Technology (NIST) is used to compute the irradiance at the wavelength setting. The monochromator is then automatically advanced to the next wavelength and the process repeated. A minimum of one flash may be used per spectral data point. The computer program can be used to set a multiple number of flashes to average at each wavelength. A complete spectral measurement requires about 2 hours, because detectors and gratings must be changed manually for each wavelength regime. The spectral passband of the pass is $5 \mathrm{~nm}$ from 280 to $1100 \mathrm{~nm}$, and $10 \mathrm{~nm}$ from 1100 to $2400 \mathrm{~nm}$, with data taken at $5-\mathrm{nm}$ resolution. 


\subsection{Optronic Laboratories (OL) Pulse Energy Measurements}

A commercial scanning spectroradiometer, the Optronic Laboratories model OL750, is available with pulse-integration capabilities. At each wavelength, an external pulse from the light source triggers the instrument. Integrating pulse circuitry then measures the amount of charge developed by the detector during the flash. In a calibrated instrument, this charge is proportional to the pulse energy $\left(\mathrm{J} / \mathrm{m}^{2} / \mathrm{nm}\right)$ at each measured wavelength. This technique can be used with Si, PMT, Ge, or InGaAs detectors, so it can cover the wavelength range from $300 \mathrm{~nm}$ in the ultraviolet (UV) through $4300 \mathrm{~nm}$ in the nearinfrared (NIR). Figure 4.5 shows the OL 750 integrating sphere, monochromator, and detector assembly in preparation for a measurement. The passband of the OL750 is about $5 \mathrm{~nm}$, with data reported at 5-nm intervals.

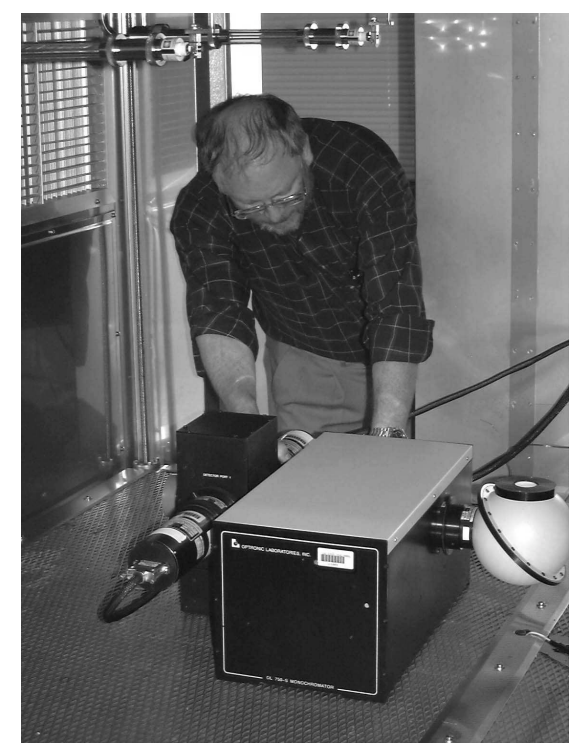

Figure 4.5. Optronic Laboratories OL-750 spectrometer for pulse integration measurements.
This system also acquires one spectral data point at each wavelength. The monochromator is set (by computer control) to a wavelength, and the lamp flash triggers the monochromator to begin integrating the pulse.

This system is also calibrated against a NIST spectral irradiance standard. However, because the system integrates the total energy within a pulse, rather than the spectral irradiance (power) at each wavelength, we compute a ratio of the pulse energy data to the PASS spectral irradiance data. This ratio file can then be applied to the pulse energy data to compute the spectral irradiance.

This system is useful for monitoring the relative spectral changes over time. A complete measurement takes about 20 minutes, compared with about two hours for the PASS system.

\subsection{Analytical Spectral Devices (ASD) Diode Array Spectrometer}

The Measurements and Instrumentation Team has recently obtained an Analytical Spectral Devices (ASD) diode array and fast-scanning spectrometer, shown in Figure 4.6, which is very compact and portable. The ASD acquires a spectrum from 350 to $2400 \mathrm{~nm}$ in $200 \mathrm{~ms}$. This acquisition time is long in comparison with the pulse simulator pulses we are interested in measuring. We collect a large number (100 to 200) of spectra with the simulator running "open loop" over about 5-10 minutes. Spectra are collected with random start and stop times, within the pulses. By computing the average of the collected spectra, the random variations in pulse samples are reduced. By measuring the simulator with the same configuration and with the same sample size in every instance, we monitor 
relative changes in the spectral distribution over time. The ASD produces data at $1-\mathrm{nm}$ intervals with a spectral passband of about $5 \mathrm{~nm}$.

As with the OL-750 pulse measurement system, we compare the ASD mean spectra with PASS measurements and determine a correction factor to convert the averaged data into what the PASS would produce in terms of absolute spectral irradiance.

\subsection{Spectral Drift of the Spire 240A Pulsed Solar Simulator}

From April 1999 to August 2000, the Measurements and Instrumentation Team measured the spectral distribution of the NREL Spire 240A solar simulator (shown in Figure 4.11) located at the NREL Outdoor Test Facility. Our goals were to (1) provide relevant spectral distributions to the NREL Measurements and Characterization Team that uses the

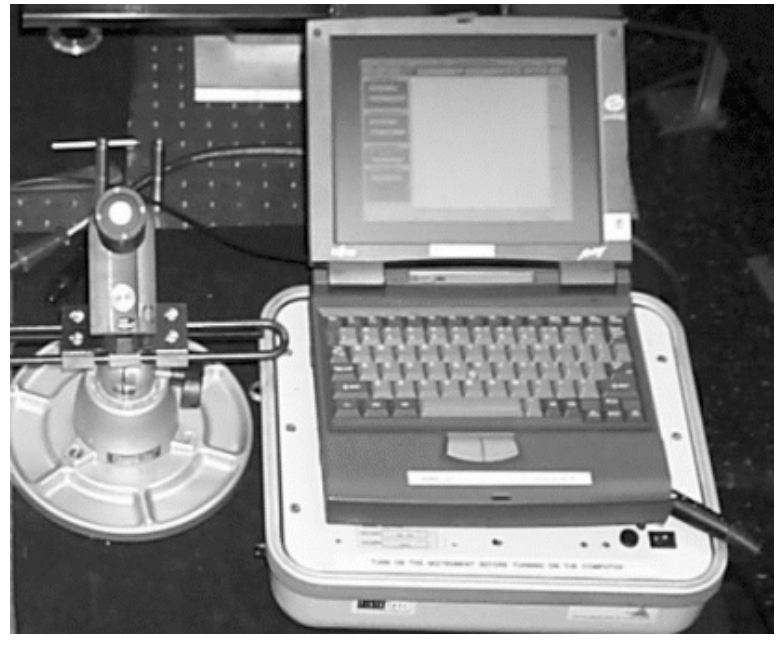

Figure 4.6. ASD Spectrometer with electronics housed under portable computer. Remote cosine receptor at left, with fiber optic link to spectrometer. simulator to establish PV module performance baselines before installation outdoors, and to periodically re-measure deployed modules to establish degradation rates. The expected total uncertainty in our measurements is $5 \%$ between 400 and $900 \mathrm{~nm}$, and $8 \%$ from 900 to $2400 \mathrm{~nm}$. The repeatability of our calibrations and measurements of the spectral standards as unknowns is about $1.0 \%$ and $2.0 \%$ in the spectral regions mentioned above.

Spectral distributions of the Spire 240A were measured on April 26, 1999, using the PASS, ASD, and OL-750 measurement systems. The PASS system measured the absolute spectral distribution, the OL-750 measured the pulse energy, and the ASD measured the relative spectral distribution. Figure 4.7 shows the relative amplitudes measured by the respective instruments. OL-750 pulse integration and ASD averaged spectra are about 2 orders of magnitude lower than the PASS spectrum. Figure 4.8 shows the three spectral distributions normalized with respect to the maximum value between 450 and $500 \mathrm{~nm}$. The normalized measurements are comparable to within about $3 \%$ in the visible region (400 to $500 \mathrm{~nm}$ ). 


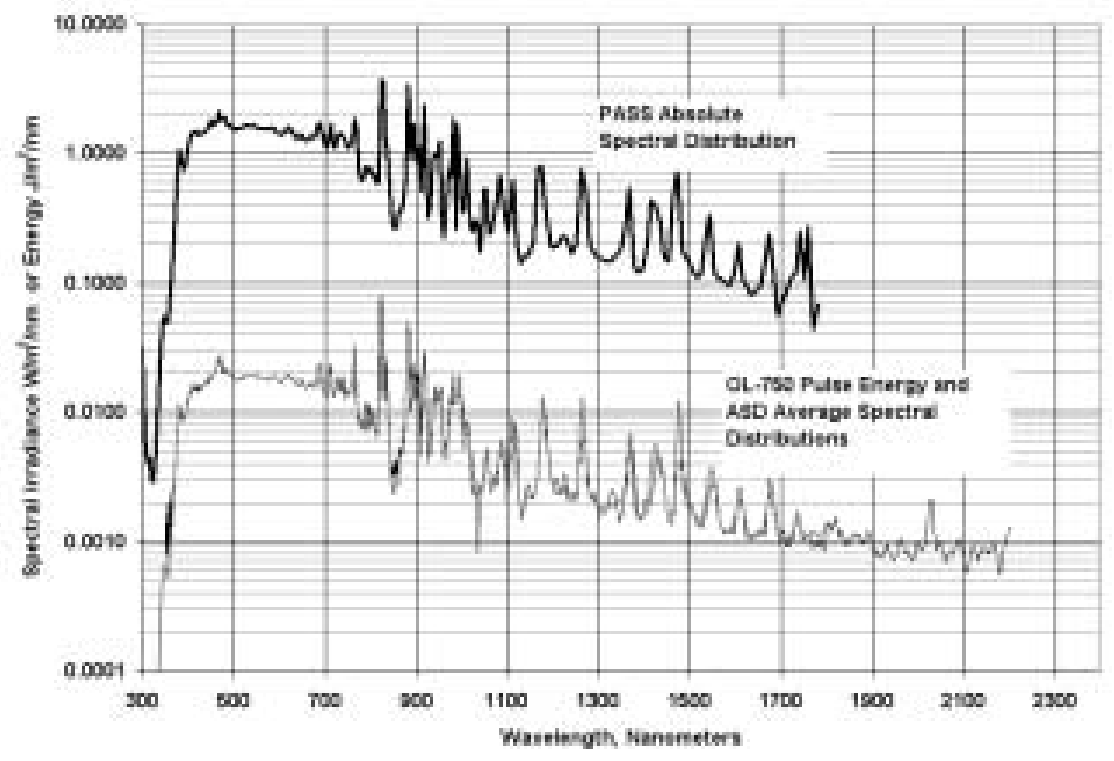

Figure 4.7. Relative magnitudes of PASS (upper curve), ASD, and OL-750 pulse integration (lower curves) spectral data on semi-logarithmic scale. Variations in detail are due to different spectral passbands of the measurements $(5 \mathrm{~nm}$ for PASS up to $1100 \mathrm{~nm}$, where it changes to $10 \mathrm{~nm}$; ASD and OL -750 passband is about $5 \mathrm{~nm}$, but the ASD data are at $1-\mathrm{nm}$ resolution and the OL-750 is at 5-nm resolution).

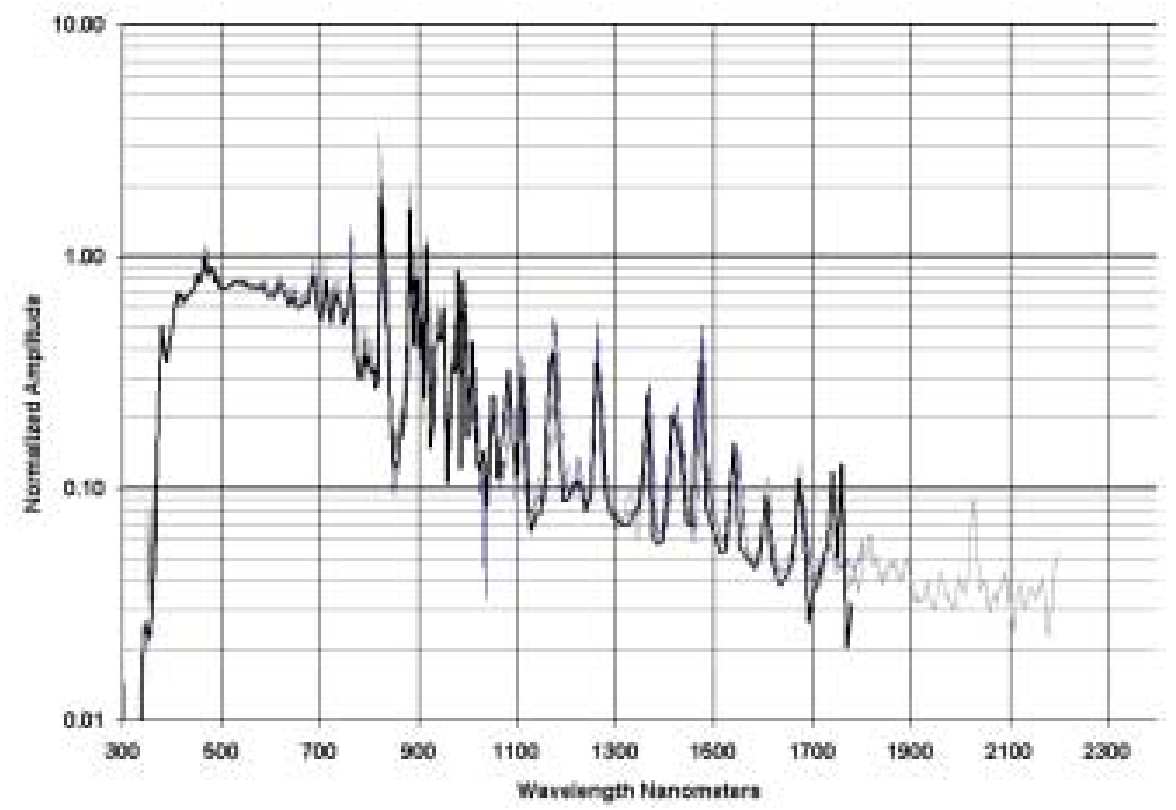

Figure 4.8. Spectral distributions of Figure 4.7 normalized to integrated maximum irradiance between 450 and $500 \mathrm{~nm}$ for each distribution. 
We made 16 monthly measurements of the Spire 240A spectral distribution between April 1999 and August 2000. The results of this monitoring show a trend of decreasing irradiance in the visible and increasing irradiance in the NIR for about the first 8 months (April 1999 to November 1999). Over the latter 8 months, the repeated spectral scans are well within our expected measurement repeatability of $2 \%$. Figure 4.9 compares the normalized OL-750 spectral irradiance in April 1999 with the latest (August 2000) OL750 measurement and a measurement using the ASD in September of 1999. The reduced intensity in the visible in the latter measurements is Figure 4.9.

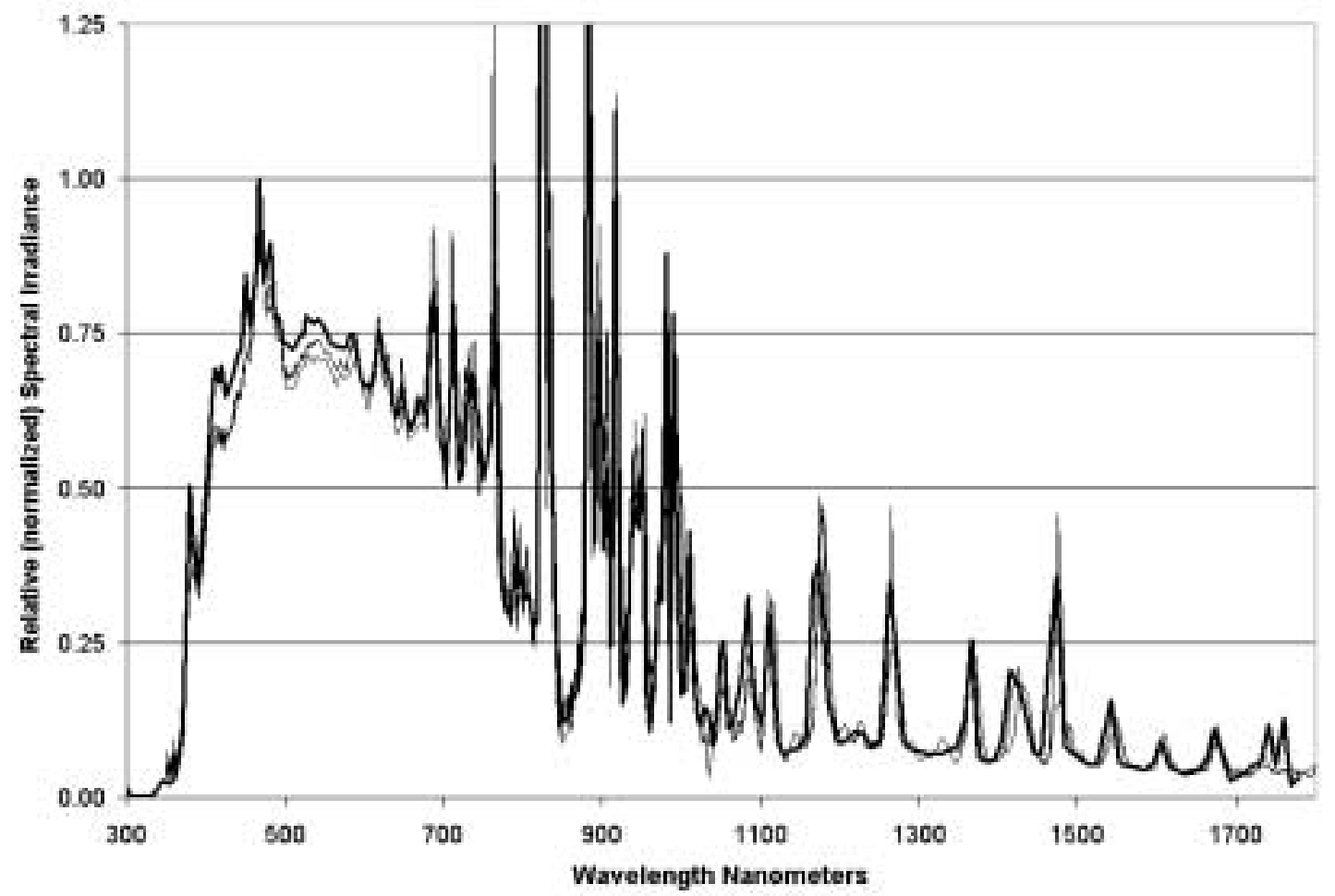

Figure 4.9 Comparison of normalized April 1999 OL-750 spectrum (heavy line) with September 1999 (lowest light line) and August 2000 OL-750 spectrum (middle thin line) showing $8 \%$ loss of energy in visible spectrum over 8 months.

clearly shown. The spectral dependence of the shift observed between the April 1999 baseline measurement and the August 2000 measurements is shown in Figure 4.10. Table 4.1 shows the total number of device measurements made in two-month periods from April 1999 to August 2000. Note the relatively high usage between May 1999 and September 1999, and in November and December of 1999. These periods of higher usage correlate with larger reductions in the relative spectral distribution in the visible, as shown in Figure 4.10.

Table 4.1. Spire 240A PV device measurements over period of spectral monitoring

\begin{tabular}{|c|c|c|c|c|c|c|c|c|c|}
\hline Period & $\begin{array}{c}\text { APR } \\
99\end{array}$ & $\begin{array}{c}\text { MAY } \\
\text { JUN 99 }\end{array}$ & $\begin{array}{c}\text { JUL } \\
\text { AUG 99 }\end{array}$ & $\begin{array}{c}\text { SEP } \\
\text { OCT 99 }\end{array}$ & $\begin{array}{c}\text { NOV } \\
\text { DEC 99 }\end{array}$ & $\begin{array}{c}\text { JAN } \\
\text { FEB 00 }\end{array}$ & $\begin{array}{c}\text { MAR } \\
\text { APR 00 }\end{array}$ & $\begin{array}{c}\text { MAY } \\
\text { JUN 00 }\end{array}$ & $\begin{array}{c}\text { JUL } \\
\text { AUG 00 }\end{array}$ \\
\hline $\begin{array}{c}\text { No. of } \\
\text { Tests }\end{array}$ & 146 & 329 & 206 & 174 & 277 & 202 & 191 & 225 & 170 \\
\hline
\end{tabular}


These results show that with relatively constant usage, on the order of 215 device measurements per month, spectral shifts of about $1.2 \%$ per month are detectable with our current measurement systems.

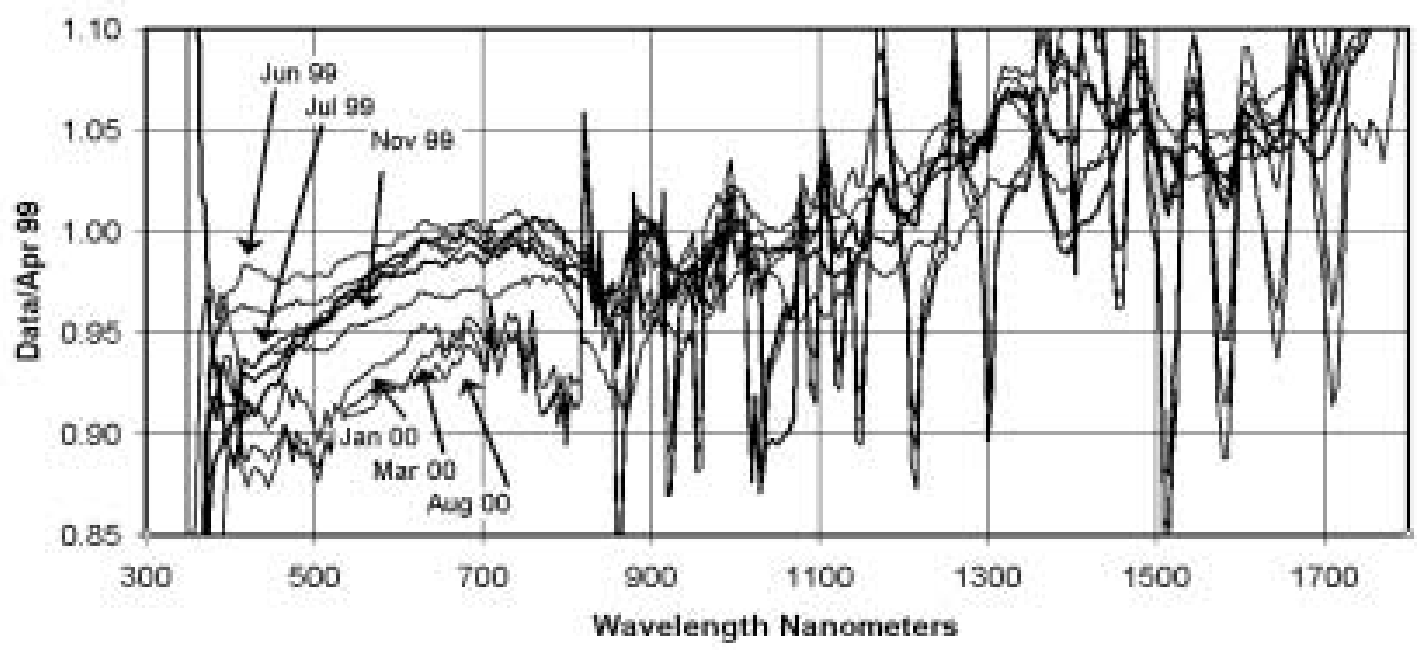

Figure 4.10. Relative shifts in spectral distribution of the NREL Spire 240A solar simulator with respect to April 1999 baseline measurement. Lines are ratios of measured data in month indicated to April 1999 measurement. Data were collected using the OL750 pulse energy measurement spectroradiometer system. Noise in ratios beyond $900 \mathrm{~nm}$ is due to variations in intensity of spectral emission lines and spectrometer wavelength drive.

A cross check on the OL-750 pulse measurement system was made in February 2000 by repeating the ASD spectrometer measurement and comparing the results with the April 1999 ASD measurements. The ratio of the ASD files essentially overlays the results obtained for the OL-750 measurements, as shown in Figure 4.11.

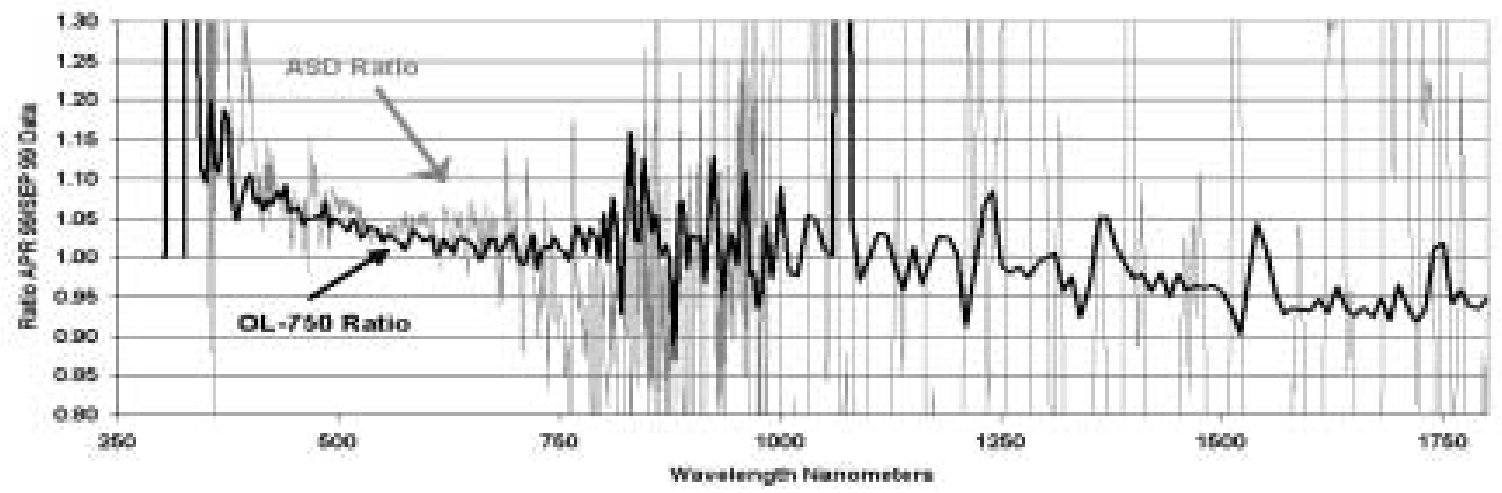

Figure 4.11. Comparison of ratio of April 1999 to September 1999 spectral data files for both ASD (light gray line) and OL-750 (black line) spectrometer systems, confirming approximately 5\% to $8 \%$ degradation in NREL Spire 240A intensity in the visible region. 


\subsection{Spectral Measurements of the NREL Spectrolab Pulse Solar Simulators}

In addition to the Spire 240A solar simulator, NREL also uses a Spectrolab pulse solar simulator that can be configured for either simulation of the ASTM reference global spectrum (Large-Area Pulse Solar Simulator, or LAPSS), or to simulate very highly concentrated solar radiation (High-Intensity Pulse Solar Simulator, or HIPSS). Figure 4.12 shows the aperture of the flash-lamp housing for the LAPPS and HIPSS.
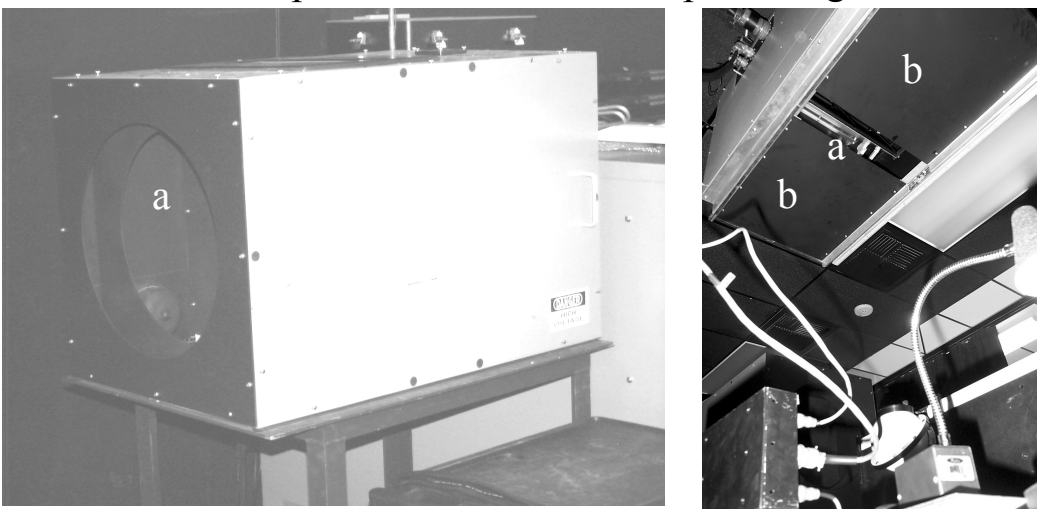

Figure 4.12. LAPSS (left) and HIPSS (right) flash lamp apertures (a). The intensity of the HIPSS is controlled by the setting of sliding shutter blades (b).

The LAPSS and HIPSS each use the same type of xenon lamp to produce the light flash. We measured the LAPSS with the PASS system and the HIPSS with the OL750 pulse integration system, and compared the relative spectral distributions with the ASTM E 892 global reference spectrum. The HIPSS intensity was set at about 10 suns. Figure 4.13 plots the relative spectral distribution of the two lamps, along with the reference global spectrum.

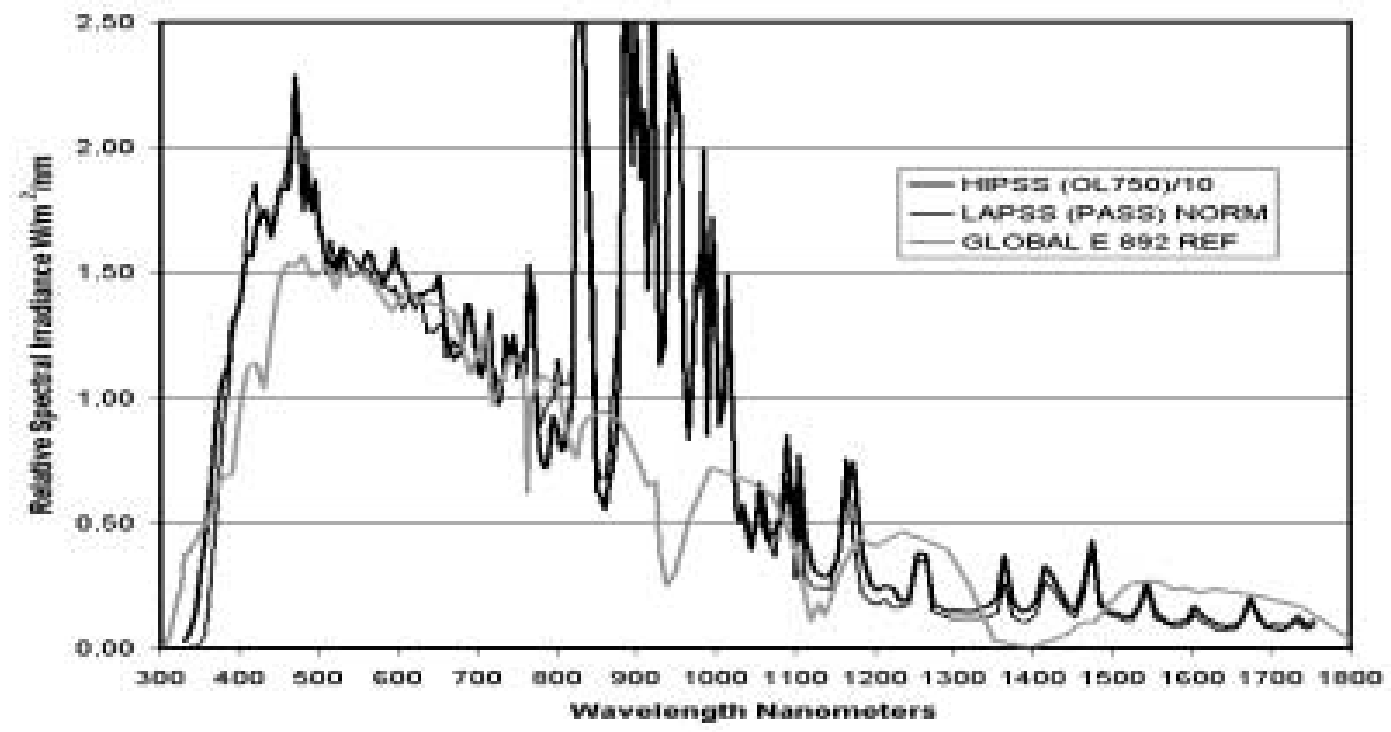

Figure 4.13. Relative spectral distribution of the normalized HIPSS (heavy line) and LAPSS (thin black line) with respect to ASTM global reference spectrum E 892 (gray line). Variations in two measured spectra are due to slightly different passbands and spectral resolution of the PASS and OL750 systems. 
These results confirm the nearly identical relative spectral distribution of the two Spectrolab lamps and permit spectral mismatch with the global reference spectrum to be calculated and applied during PV device testing. They also imply that the PASS and OL750 measurement systems provide consistent results and can be used interchangeably in many measurement applications.

\subsection{Upgrading Solar Radiation Research Laboratory Instrumentation}

The Solar Radiation Research Laboratory (SRRL) was established at the top of the NREL South Table Mountain Site in the summer of 1985. Since that time, the SRRL has continuously recorded solar and meteorological data for use by NREL researchers in outdoor tests of renewable energy systems. In December of 1999, a new building and measurement platform for SRRL was completed. The facility integrates the solar measurement and research activities, NREL metrology laboratory, and NREL optical metrology laboratory in a single building. Figure 5.1 shows the new facility and the new instrument mounting platform.
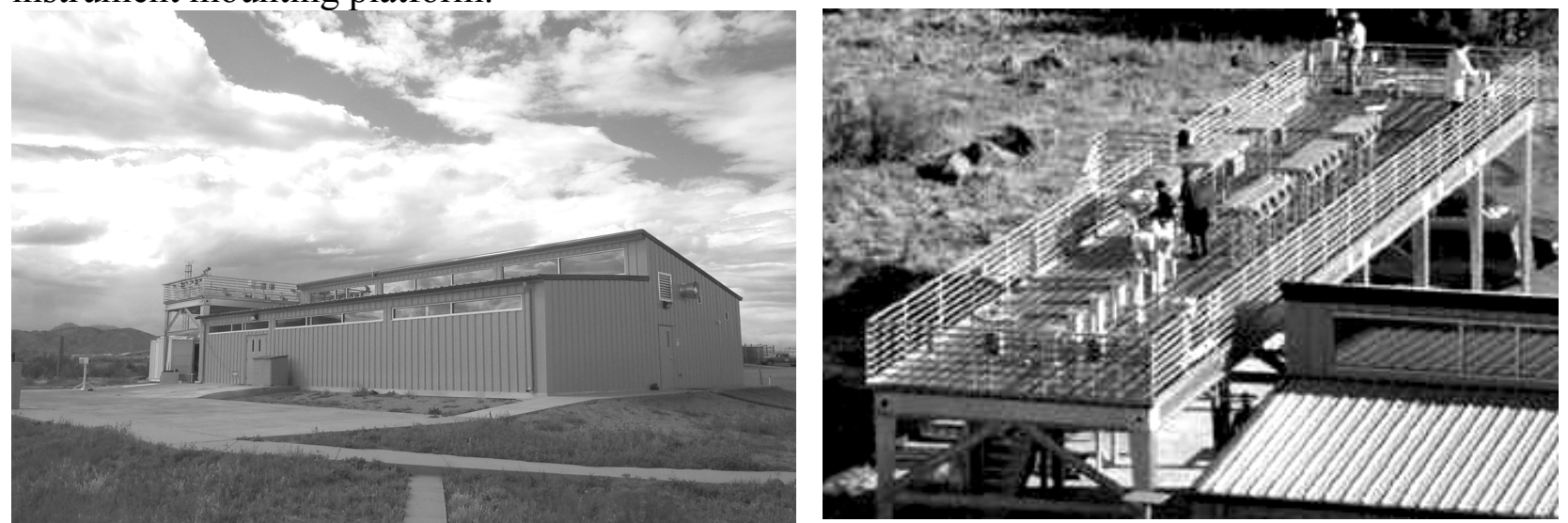

Figure 5.1. New SRRL/Metrology/Optics Lab building (left) and solar radiation measurement platform to west of building (right).

\subsection{Baseline Measurement System}

Since the inception of SRRL measurement activities, basic solar and meteorological measurements have been made at the SRRL site. These "baseline measurement systems," or BMS measurements, include direct-normal, global-horizontal, and diffuse-horizontal (under a shadowband) solar radiation, and ambient temperature, relative humidity, barometric pressure, and wind speed and direction. At various times, other measurement parameters such as global $40^{\circ}$ tilt south-facing solar radiation, global-normal (suntracking pyranometer), longwave infrared, and tracking shading disk diffuse-sky measurements have been added to the BMS complement of instrumentation. As of 1995, current and historical measurement data (as of April 1985) have been available over the Internet at http://srrl.nrel.gov/ since January 1997. Current and historical data can be viewed in graphical format or downloaded as ASCII files. 
Recent additions to the BMS that include two tools for mapping sky cloud cover and sky radiance and illuminance, an all-sky camera and a sky-dome radiance mapping instrument.

\subsection{Sky Camera Archive and Sky Radiance Mapping}

A digital camera with a fish-eye lens has been installed under a protective plastic dome for capturing all-sky images on a real-time basis. Archives of historical images taken at the beginning of each hour are digitally recorded and can be retrieved individually or in a "gallery" format showing the hourly progression of sky conditions over any user elected period. Figure 5.2 shows images for each hour from 6 A.M. to 6 P.M. on September 2, 2000.

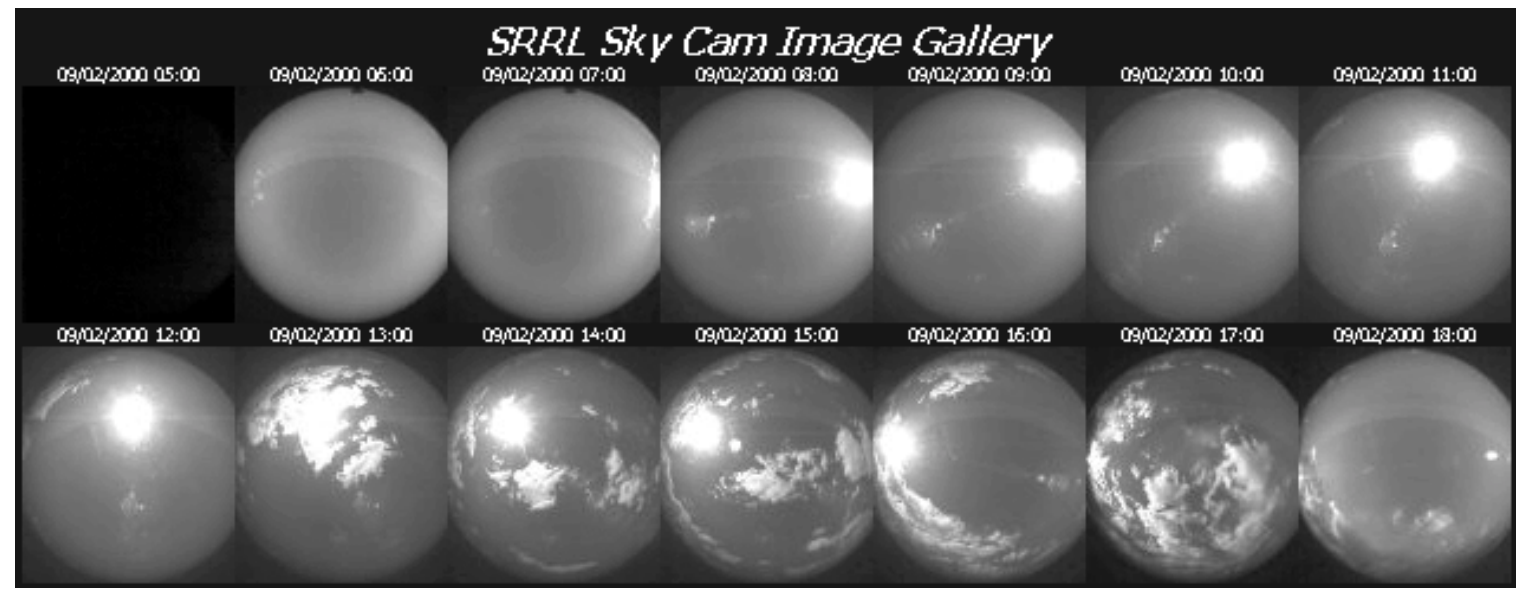

Figure 5.2. SRRL all-sky camera gallery for September 2, 2000.

A more quantitative measure of sky radiance and illuminance over the sky dome is measured with an Eko model MS300LR sky scanner that samples sky illuminance (kiloCandelas per square meter) and radiance $\left(\mathrm{W} / \mathrm{m}^{2} / \mathrm{sr}\right.$ ) at 145 locations covering the sky dome. Figure 5.3 is a comparison of sky-dome illuminance and a sky-camera image for noon on June 15, 2000.

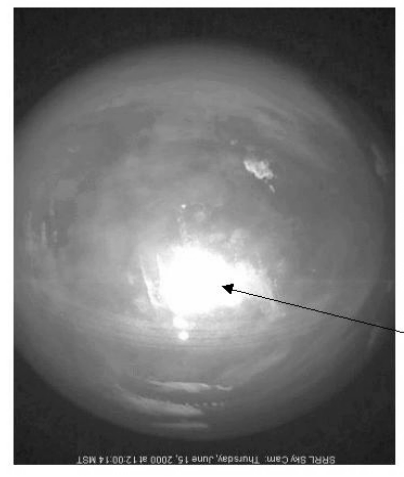

Sky Cam (inverted \& Reflected)

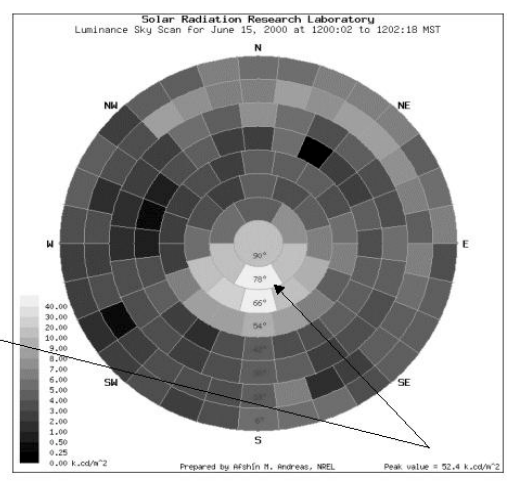

Sky Scan Illuminance Map 15 Jun 12:00 AM

Figure 5.3. Sky luminance plot (right) compared with sky camera image for noon 15 June 2000 showing brightness distribution around noontime sun. Arrows locate sun's position. 
Another quantitative application of the digital sky scanner radiance data is to integrate the angularly resolved data to compare with diffuse-sky measurements. Figure 5.4 compares the angularly integrated value of the sky scanner radiance data with a black-and-white pyranometer (Eppley Model 8-48) under a tracking shading disk.

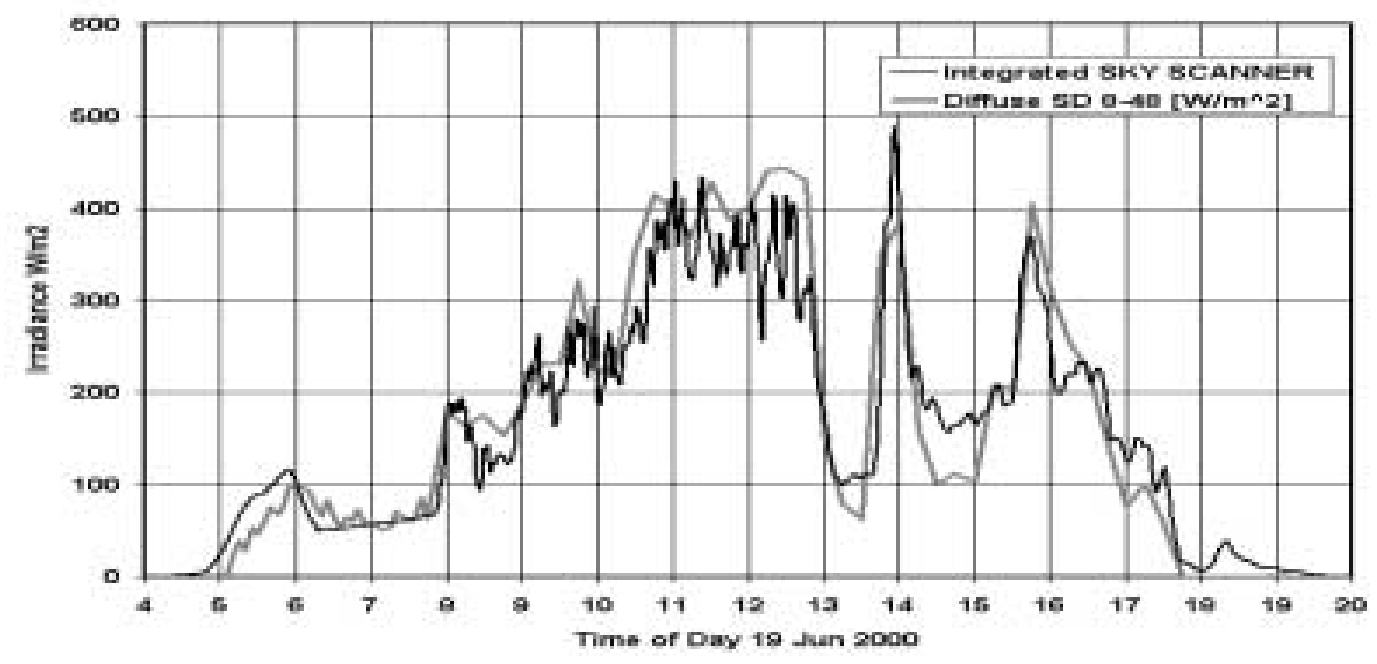

Figure 5.4. Comparison of diffuse-sky measurements by black-and-white pyranometer under tracking shading disk (black line) with integrated Eko sky scanner radiance data (gray line) for June 19, 2000. The diffuse pyranometer data are 1-minute data, the skyscanner data are the integral of measurements archived at 15-minute intervals.

The sky scanner can be used to map out the angular distribution of the diffuse-sky component and compute the relative contribution of each sky dome element to the overall reference diffuse irradiance during BORCAL events, as shown in Figure 5.5.

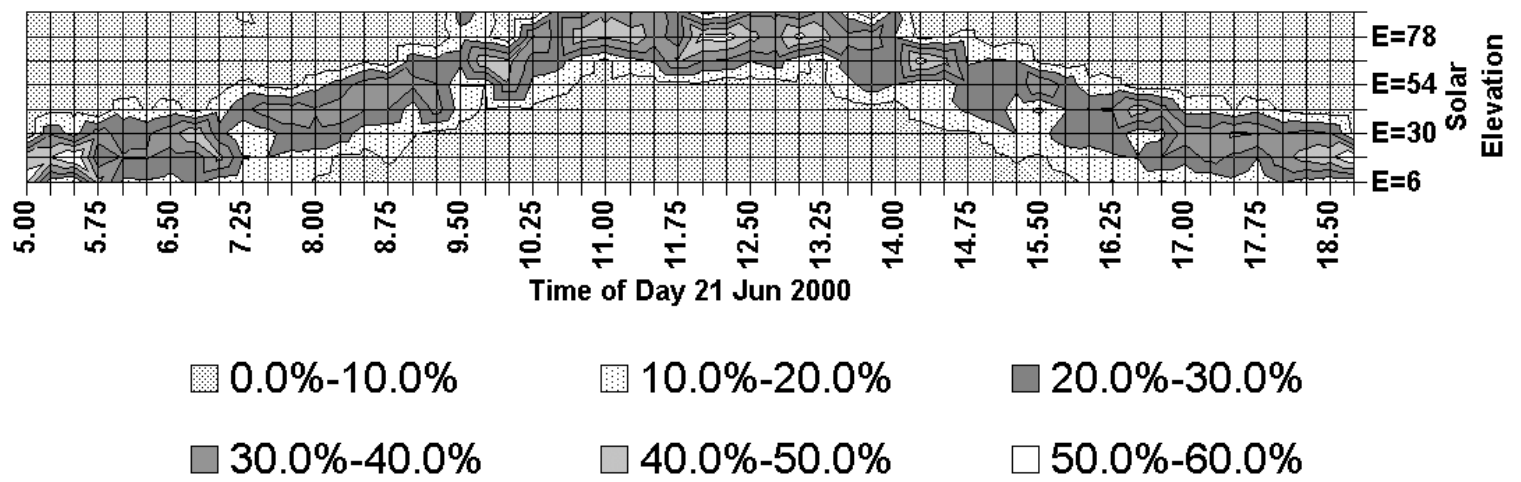

Figure 5.5. Plot of relative contribution (percent) of diffuse-sky radiance to the total diffuse-sky component during BORCAL event 2000-01, June 21, 2000. Contours show percent of total diffuse sky for each zenith/elevation angle element of the sky as a function of time of day. 


\subsection{New SRRL Baseline Measurement Instrumentation}

The completion of the new SRRL facilities provided the opportunity to expand and upgrade the baseline measurement system suite of instruments and measurements. Although not complete as of this writing (September 2000), the BMS system has been redesigned to accommodate the 45 measurement systems and parameters shown in Figure 5.6.
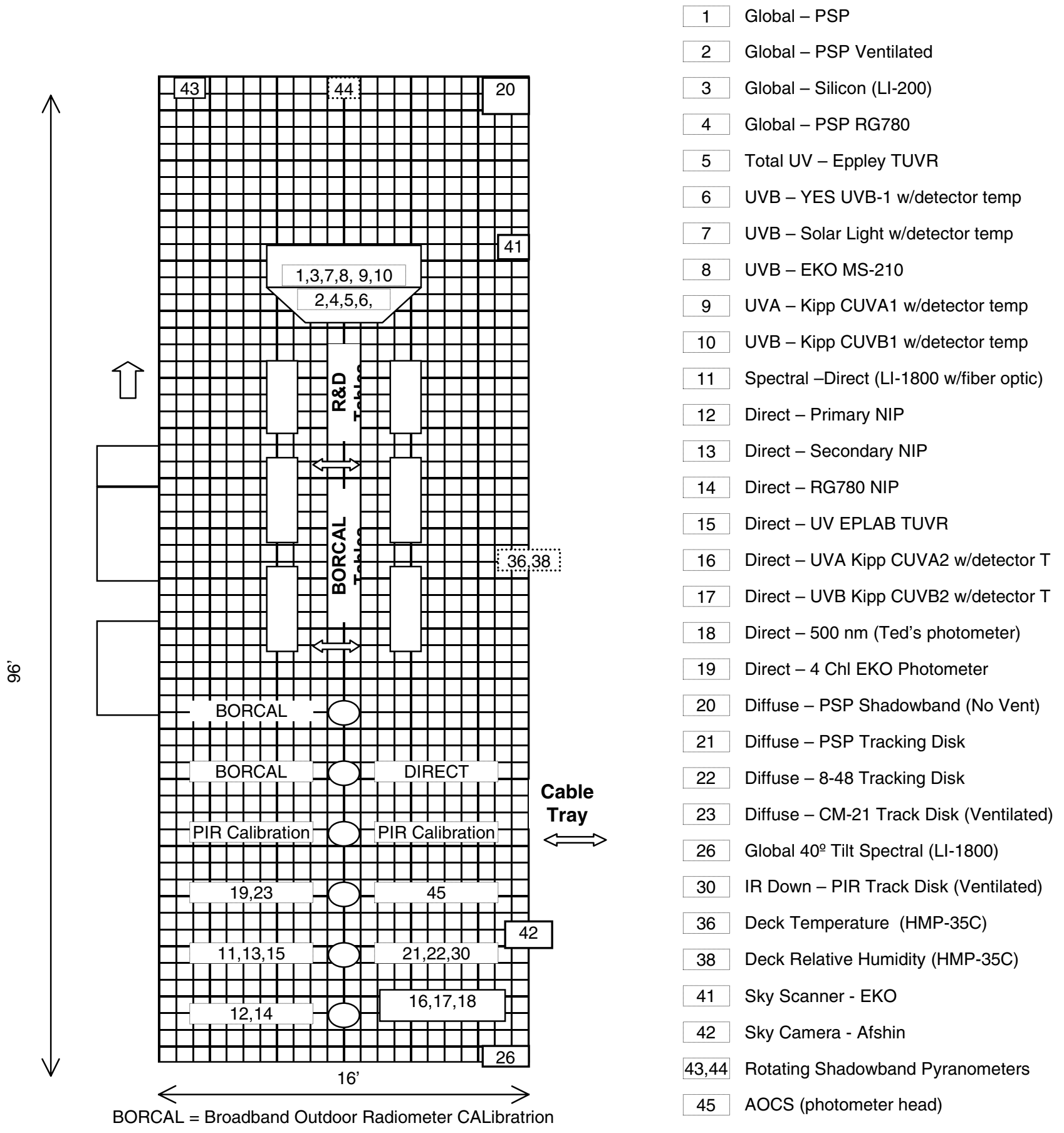

Figure 5.6. SRRL Baseline Measurement Platform and instrument complement. 
Most of this new instrumentation will be sampled at 1-minute intervals for archive purposes. The sky camera, sky scanner, and spectral (direct-normal and global-tilted) measurements will be archived less frequently; but an Internet user will be able to capture data from these instruments in nearly real time (i.e., the latest data will be available when a user accesses the instrument parameter).

Infrared sensors (pyrgeometers) are valuable for research into thermal offsets in solar pyranometers and the thermal environment and energy exchange between modules and the sky and ground. Ultraviolet data for the UVA (315 to $400 \mathrm{~nm}$ ) and UVB (280 to 315 $\mathrm{nm}$ ) spectral regions will be useful for material exposure and degradation studies. Spectral data will add to the existing SERI Spectral Solar Irradiance Data Base (Riordan et al., 1990a; 1990b; Riordan et al., 1989). Broadband solar radiation components measured in various classical (global-horizontal) and PV collector configurations (tracking flat-plate, latitude-tilt flat-plate) will assist in validating solar radiation models and PV performance and deployment models. Finally, the SRRL instrument platform will also serve as a venue for testing and evaluating new renewable energy and climate research radiometer technology and measurement and modeling techniques.

\subsection{Conclusions}

Recent improvements (during 2000) in broadband radiometer calibrations result in the removal of bias errors on the order of 20 watts per square meter $\left(\mathrm{W} / \mathrm{m}^{2}\right)$ in the calibration of pyranometers for the measurement of global-hemispherical solar radiation. Using black-and-white pyranometers with low thermal offsets to measure the diffuse-sky irradiance removes the $20 \mathrm{~W} / \mathrm{m}^{2}$ bias error in the reference irradiance during calibrations. The use of global-positioning-system technology to determine time and location has reduced uncertainty in the calculation of zenith angles to less than $0.06 \%$. The combination of new equipment and a re-analysis of the total uncertainty in our outdoor calibrations produce about a $15 \%$ overall reduction in the uncertainty of responsivities for pyranometers. Application of zenith-angle-dependent responsivities derived from RCC calibrations can further reduce the uncertainty in pyranometer field measurements from over $5 \%$ to less than $2 \%$ (or from $50 \mathrm{~W} / \mathrm{m}^{2}$ to $20 \mathrm{~W} / \mathrm{m}^{2}$ at $1000 \mathrm{~W} / \mathrm{m}^{2}$ intensity) in many instances. A program of periodic measurements of the spectral distribution of pulse solar simulators has shown we can detect a $1.5 \%$ shift in spectral distribution over the period of a month. Multiple spectral measurement systems produce nearly identical results in the monitoring of several source systems, giving us confidence in our measurement results. New equipment has been purchased and will be installed in the redesigned Solar Radiation Research Laboratory (SRRL) Baseline Measurement System (BMS). Expanded measurement capability, including sky-radiance mapping, extensive ultraviolet and infrared radiation measurements, and routine spectral sampling, will provide a unique complement of data for investigating PV device, module, and system design and performance, model development and validation, and evaluating new measurement systems. 


\subsection{References}

ASTM 1997a, "Tables for Terrestrial Direct Normal Spectral Irradiance for Air Mass 1.5," ASTM E891-87. 1997 Annual Book of ASTM Standards, Vol. 14. American Society for Testing and Materials, 1916 Race Street, Philadelphia, PA 19103.

ASTM 1997b, "Tables for Terrestrial Solar Spectral Irradiance at Air Mass 1.5 for a $37^{\circ}$ Tilted Surface," ASTM E892-87. 1997 Annual Book of ASTM Standards, Vol. 14. American Society for Testing and Materials, 1916 Race Street, Philadelphia, PA 19103.

ASTM 1997c, "Standard Test Method for Calibration of Pyrheliometers by Comparison to Reference Pyrheliometers," ASTM E-816-95. 1997 Annual Book of ASTM Standards, Vol. 14. American Society for Testing and Materials, 1916 Race Street, Philadelphia, PA 19103.

ASTM 1997d, "Standard Method for Calibration of Reference Pyranometers with Axis Vertical by the Shading Method," ASTM E-913-82. 1997 Annual Book of ASTM Standards, Vol. 14. American Society for Testing and Materials, 1916 Race Street, Philadelphia, PA 19103.

ASTM 1994, "Standard Specification for Solar Simulation for Terrestrial Photovoltaic Testing," ASTM E927-91. 1994 Annual Book of ASTM Standards, Vol. 12.02. American Society for Testing and Materials, 1916 Race Street, Philadelphia, PA 19103.

ASTM 1998, "Standard Practice for Determination of the Spectral Mismatch Parameter Between a Photovoltaic Device and a Photovoltaic Reference Cell," ASTM E973M-96. 1998 Annual Book of ASTM Standards, Vol. 12.02. American Society for Testing and Materials, 1916 Race Street, Philadelphia, PA 19103.

Dutton et al., 2000, "Measurement of Broadband Diffuse Solar Irradiance Using Current Commercial Instrumentation with a Correction for Thermal Offset Errors." Journal of Atmospheric and Oceanic Technology, American Meteorological Society, in press.

Fluke, 1990. Helios Plus 2287A Data Acquisition Front End System Manual Vol 1. John Fluke Mfg. Co.

Gulbrandsen, A., 1978, Journal of Applied Meteorolog, 17, pp. 899-904.

Iqbal. M., 1983, An Introduction to Solar Radiation, Academic Press, New York.

Kendall, J.M., and C.M. Berhdahl, 1970, "Two Blackbody Radiometers of High Accuracy," Applied Opticsl 12, pp. 1089-1091.

Kroposki, B., D. Myers, K. Emery, L. Mrig, C. Whitaker, and J. Newmiller, 1996, Photovoltaic Module Energy Rating Methodology Development. 6 pp, National Renewable Energy Laboratory Technical Report, NREL/TP-411-20412. 
Maxwell, E. L., and D.R Myers, 1992, Daily Estimates of Aerosol Optical Depth for Solar Radiation Models. Burley, S.; Arden, M. E., eds. Solar '92: Proceedings of the 1992 Annual Conference of the American Solar Energy Society, 15-18 June 1992, Cocoa Beach, Florida. Boulder, CO: American Solar Energy Society; pp. 323-327.

Michalsky, J., 1988a, The Astronomical Almanac's Algorithm for Approximate Solar Position (1950-2050). Solar Energy 40 (3), 227-235.

Michalsky, J., 1988b, ERRATA: The Astronomical Almanac's Algorithm for Approximate Solar Position (1950-2050). Solar Energy 41 (1), 113.

Myers, D.R., 1988, "Uncertainty Analysis for Thermopile Pyranometer and Pyrheliometer Calibrations Performed by SERI." Solar Energy Research Institute (now Renewable Energy Laboratory), SERI/TR-215-3294.

Myers, D.R., K.A. Emery, and T.L. Stoffel. 1989."Uncertainty Estimates for Global Solar Irradiance Measurements Used to Evaluate PV Device Performance." Solar Cells 7, pp. 455-464.

Myers, D.R., 1989, "Application of a Standard Method of Uncertainty Analysis to Solar Radiometer Calibrations." Solar '89 Technical Papers: Proceedings of the 1989 Annual Conference, American Solar Energy Society. pp. 445-449.

Myers, D.R., and T.L. Stoffel, 1990, "A Description of the Solar Radiometer Calibration (RADCAL) Process at SERI." Solar '90 Technical Papers: Proceedings of the 1990 Annual Conference, American Solar Energy Society. pp. 171-177.

Myers, D.R., and E.L. Maxwell, 1992, Hourly Estimates of Precipitable Water for Solar Radiation Models. Burley, S.; Arden, M. E., eds. Solar 92: Proceedings of the 1992 Annual Conference of the American Solar Energy Society, 15-18 June 1992, Cocoa Beach, Florida. Boulder, CO: American Solar Energy Society; pp. 317-322.

NREL, 1997, RCC Radiometer Calibration and Characterization. Data Acquisition and Data Base Software for the Calibration and Characterization of Pyranometers and Pyrheliometers. NREL Metrology Manual.

Reda, I., 1996, Calibration of a Solar Absolute Cavity Radiometer with Traceability to the World Radiometric Reference. 79 pp., NREL Technical Report/TP-463-20619, National Renewable Energy Laboratory.

Reda, I., T. Stoffel, and J. Treadwell, 1996, NPC1996, "Results of NREL Pyrheliometer Comparisons NPC 1996." NREL Internal Metrology Report.

Reda, I., T. Stoffel, and J. Treadwell, 1997, NPC1997, "Results of NREL Pyrheliometer Comparisons NPC 1997." NREL Internal Metrology Report. 
Reda, I., T. Stoffel, and J. Treadwell, 1998, NPC1998, "Results of NREL Pyrheliometer Comparisons NPC 1998." NREL Internal Metrology Report.

Reda, I., T. Stoffel, and J. Treadwell, 1999, NPC1999, "Results of NREL Pyrheliometer Comparisons NPC 1999." NREL Internal Metrology Report.

Reda, I. and D. Myers, 1999, "Calculating the Diffuse Responsivity of Solar Pyranometers," NREL Technical Report/TP-560-26483, National Renewable Energy Laboratory.

Riordan, C.J, D.R. Myers, and R.L. Hulstrom, 1990a, Spectral Solar Radiation Data Base, Vol. I, SERI Technical Report/TR215-3513A.

Riordan, C.J, D.R. Myers, R.L. Hulstrom, 1990b, Spectral Solar Radiation Data Base Documentation, Vol. II, SERI Technical Report/TR215-3513B.

Riordan, C., D. Myers, M. Rymes, R. Hulstrom, W. Marion, C. Jennings, and C. Whitaker, 1989, "Spectral Solar Radiation Data Base at SERI," Solar Energy 42(1), 1989; pp. 67-69.

Stoffel, T.L., Reda, I, Myers, D.R., Renne, D.,Wilcox, S, Treadwell, J. "Current Issues in Terrestrial Solar Radiation Instrumentation for Energy, Climate, and Space Applications" Presented at 7th International Conference on New Developments and Applications in Optical Radiometry, NEWRAD99, Madrid Spain, Oct 23-26 1999. To be published in Metrologia, Journal of the International Bureau of Weights and Measures (BIPM) Vol 54, 2000.

Wilcox, S.M., I. Reda, D.A. Nelson, and C. Webb, 1999, "Traceability and Verification of Radiometer Calibrations at the Southern Great Plains Radiometer Calibration Facility," In Proceedings of the Ninth Annual ARM Science Team Meeting, Ed. by N. Burleigh and D. Carrothers, U.S. Department of Energy, Richland, WA.

Wilcox, S.M., and T.L. Stoffel, 1998, "Radiometer Calibrations at the ARM Southern Great Plains Radiometer Calibration Facility," In Proceedings of the Eighth Annual ARM Science Team Meeting, Ed. by N. Burleigh and D. Carrothers, U.S. Department of Energy, Richland, WA.

Willson, R.C. 1973. "Active Cavity Radiometer," Applied Optics 12, pp. 810-817.

WMO 1983, Guide to Meteorological Instruments and Methods of Observation WMO No. 8 , Secretariat of the World Meteorological Organization, Geneva, Switzerland.

Zerlaut, G.A., 1986, "Solar Radiometry Instrumentation, Calibration, Techniques and Standards," Solar Cells 18, pp. 189-203.

Zerlaut, G.A., 1989, "Solar Radiation Instrumentation," in Solar Resources, R. Hulstrom, Ed. MIT Press, Massachusetts Institute of Technology. 
Zimmerman, J.C., 1981, "Sun Pointing Algorithms and Their Accuracy," SAND81-0761, Experimental Systems Operation Division, 4721, Sandia National Laboratories, Albuquerque, NM. 
Public reporting burden for this collection of information is estimated to average 1 hour per response, including the time for reviewing instructions, searching existing data sources,

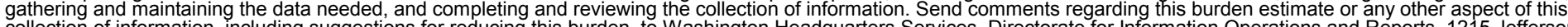

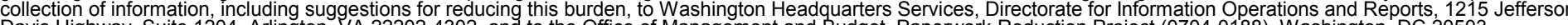
Davis Highway, Suite 1204, Arlington, VA 22202-4302, and to the Office of Management and Budget, Paperwork Reduction Project (0704-0188), Washington, DC 20503.
1. AGENCY USE ONLY (Leave blank)
2. REPORT DATE
3. REPORT TYPE AND DATES COVERED
Technical Report
October 2000

4. TITLE AND SUBTITLE

5. FUNDING NUMBERS

$\mathrm{C}$ :

6. $\operatorname{AUTHOR}(\mathrm{S})$

D.R. Myers, T.L. Stoffel, A. Andreas, S. Wilcox, and I. Reda

TA: PVP17401

7. PERFORMING ORGANIZATION NAME(S) AND ADDRESS(ES)

8. PERFORMING ORGANIZATION REPORT NUMBER

9. SPONSORING/MONITORING AGENCY NAME(S) AND ADDRESS(ES)

National Renewable Energy Laboratory

1617 Cole Blvd.

Golden, CO 80401-3393

10. SPONSORING/MONITORING AGENCY REPORT NUMBER

NREL/TP-520-28941

11. SUPPLEMENTARY NOTES

NREL Technical Monitor:

12a. DISTRIBUTION/AVAILABILITY STATEMENT

National Technical Information Servce

12b. DISTRIBUTION CODE

U.S. Department of Commerce

285Port Royal Road

Springfield, VA 22161

13. ABSTRACT (Maximum 200 words) The Photovoltaic Radiometric Measurements Task has improved broadband and spectral measurement capabilities at NREL. These improved NREL's capabilities affect the Photovoltaic Module and Array Performance and Reliability and Photovoltaic Measurements and Characterization Projects. Recent improvements (during 2000) in broadband radiometer calibrations result in the removal of bias errors on the order of 20 watts per square meter $\left(\mathrm{W} / \mathrm{m}^{2}\right)$ in the measurement of global-hemispherical solar radiation. The improvements described are partially due to technical interactions by members of the Measurements and Instrumentation Team with the U.S. Department of Energy Atmospheric Radiation Measurement Program (ARM), National Aeronautics and Space Administration (NASA) Earth Observing System (EOS) Validation Program, World Meteorological Organization (WMO) Baseline Surface Measurement Network (BSRN), and National Oceanic and Atmospheric Administration (NOAA) Solar Radiation Research Branch (SRRB). New equipment has been purchased and techniques have been developed to characterize pulsed solar simulator spectral distributions. New equipment has been purchased and will be installed in the redesigned Solar Radiation Research Laboratory (SRRL) Baseline Measurement System (BMS). Expanded measurement capability, including sky radiance mapping, extensive ultraviolet and infrared radiation measurements, and routine spectral sampling will provide a unique complement of data for investigating PV device, module, and system design and performance, model development and validation, and for evaluating new measurement systems.

14. SUBJECT TERMS

photovoltaics ; broadband and radiometer calibrations ; hemispherical solar radiation ; solar simulator spectral distributions ; sky radiance mapping; extensive ultraviolet and infrared radiation measurements ; system design and performance ; RCC/BORCAL ; SRRL ; total 15. NUMBER OF PAGES uncertainty calculation

16. PRICE CODE

17. SECURITY CLASSIFICATION OF REPORT Unclassified
18. SECURITY CLASSIFICATION OF THIS PAGE Unclassified
19. SECURITY CLASSIFICATION OF ABSTRACT Unclassified
20. LIMITATION OF ABSTRACT

UL 